\title{
IN DEFENSE OF SECONDARY PHARMACEUTICAL PATENTS: A RESPONSE TO THE UN'S GUIDELINES FOR PHARMACEUTICAL PATENT EXAMINATION
}

\author{
CHRistopher M. HOLMAN ${ }^{*}$
}

\begin{abstract}
In 2015, the United Nations Development Programme issued a document entitled Guidelines for Pharmaceutical Patent Examination: Examining Pharmaceutical Patents from a Public Health Perspective (the "Guidelines"). The heart of the Guidelines is a category-by-category examination of twelve types of "secondary" pharmaceutical patent claims: Markush claims; selection patents; polymorphs; enantiomers; salts; ethers and esters; compositions; doses; combinations; prodrugs; metabolites; and new medical uses. The Guidelines advise patent offices to apply heightened patentability requirements to these claims in a manner that would effectively deny patent protection to important pharmaceutical innovations currently afforded patent protection. In particular, the Guidelines postulate that many forms of pharmaceutical innovation are inherently routine, and absent some sort of exceptional circumstance should be treated as obvious/non-inventive, and hence unpatentable. In my experience, however, the Guidelines' assumption that many types of pharmaceutical inventions are inherently obvious and undeserving of patent protection is incorrect and based on an oversimplified view of how these inventions come about. This Article provides an evidence-based response to the Guidelines that refutes, or at least qualifies, some of the significant conclusions and recommendations set forth by its author.
\end{abstract}

\section{INTRODUCTION}

In 2015, the United Nations Development Programme (UNDP) issued a document entitled Guidelines for Pharmaceutical Patent Examination: Examining Pharmaceutical Patents from a Public Health Perspective (the "Guidelines"). ${ }^{1}$ The Guidelines represent a follow-up to an earlier document, Guidelines for the Examination of Pharmaceutical Patents: Developing a Public Health Perspective-Working Paper (the "Working Paper"), which was published in 2007 as a "working paper" by the International Centre for Trade and Sustainable Development (ICTSD), the United Nations Conference on Trade and Development (UNCTAD), and the World Health Organization (WHO). ${ }^{2}$

* Professor of Law, University of Missouri-Kansas City School of Law; J.D., University of California, Berkeley; Ph.D., University of California, Davis. Thanks to the Geneva Network for generous support in the preparation of this Article. The views expressed herein are entirely those of the author.

1. Carlos M. Correa, Guidelines for Pharmaceutical Patent Examination: Examining Pharmaceutical Patents from a Public Health Perspective, UNDP (2015), http://www.ipwatch.org/2016/06/15/un-development-agency-issues-guidelines-for-pharmaceutical-patentexaminers/ [https://perma.cc/K683-26BQ] [hereinafter Guidelines].

2. Carlos M. Correa, Guidelines for the Examination of Pharmaceutical Patents: 
Although the analysis and recommendations set forth in the Guidelines largely track the Working Paper, there are some fairly significant differences, reflecting post-2007 developments and, in the words of its author, "the benefit of an expert review process" involving a number of "experts in the field.".

The heart of the Guidelines is a category-by-category examination of twelve types of pharmaceutical patent claims: Markush claims; ${ }^{4}$ selection patents; ${ }^{5}$ polymorphs $;{ }^{6}$ enantiomers $;$ salts $;{ }^{8}$ ethers and esters $;{ }^{9}$ compositions $;{ }^{10}$ doses $;{ }^{11}$ combinations; ${ }^{12}$ prodrugs $;{ }^{13}$ metabolites $;{ }^{14}$ and new medical uses. ${ }^{15}$ Patents with claims of this type are sometimes referred to as "secondary" pharmaceutical patents, distinguished from "primary" patents directed toward a novel active ingredient. ${ }^{16}$ There are those who consider secondary pharmaceutical patent claims somehow less legitimate and worthy of protection than primary claims, and less necessary for incentivizing pharmaceutical innovation. ${ }^{17}$ Some developing countries have sought to curtail their patentability. ${ }^{18}$ For example, India excludes from patentability the

mere discovery of a new form of a known substance which does not result in the enhancement of the known efficacy of that substance or the mere discovery of any new property or new use for a known substance or of the mere use of a known process, machine or apparatus unless such known process results in a new product or employs at least one new reactant. ${ }^{19}$

Developing a Public Health Perspective-Working Paper (Int'l Ctr. for Trade and Sustainable Dev., Word Health Org., \& U.N. Conference on Trade and Dev.) (Jan. 2007), http://www.ictsd.org/sites/default/files/research/2008/06/correa_patentability20guidelines.pdf [https://perma.cc/YFF3HUJF] [hereinafter Working Paper].

3. Guidelines, supra note 1 , at 4.

4. See infra Part I.

5. See infra Part II.

6. See infra Part III.

7. See infra Part IV.

8. See infra Part V.

9. See infra Part VI.

10. See infra Part VII.

11. See infra Part VIII.

12. See infra Part IX.

13. See infra Part X.

14. See infra Part XI.

15. See infra Part XII.

16. Amy Kapczynski et al., Polymorphs and Prodrugs and Salts (Oh My!): An Empirical Analysis of "Secondary" Pharmaceutical Patents, 7 PLOS ONE 1, 1 (Dec. 2012).

17. Id. at 2 .

18. Id.

19. Patents Act, No. 15 of 2005, § 3(d) INDIA CODE (2005); see also Working Paper, supra note 2 , at 10 . 
Brazil and South Africa are reportedly considering legislation along similar lines. ${ }^{20}$

The Guidelines provide "recommendations" as to how patent examiners should examine these secondary pharmaceutical patent claims in a manner that would, according to the author of the Guidelines, "protect public health and promote access to medicines." 21 The recommendations generally call for heightened patentability requirements, which, if implemented, would essentially deny patent protection to various types of pharmaceutical innovation that are currently afforded patent protection. ${ }^{22}$ The Working Paper has been widely cited and used as the basis of arguing that heightened requirements of patentability should be applied to pharmaceutical inventions. ${ }^{23}$ No doubt the release of the finalized Guidelines will serve to add more fuel to the fire.

One of the primary means by which the objective of the Guidelines would be accomplished is through a more rigorous application of the nonobviousness/inventive step requirements of patent law. In particular, the Guidelines postulate that many forms of pharmaceutical innovation are inherently routine, and that absent some sort of exceptional circumstance they should be treated as obvious/non-inventive, and hence unpatentable. ${ }^{24}$ In my experience, though, the Guidelines' assumption that many types of pharmaceutical inventions are inherently obvious and undeserving of patent protection is incorrect and based on an oversimplified view of how these inventions come about. This Article provides an evidence-based response to the Guidelines that refutes, or at least qualifies, some of the significant conclusions and recommendations set forth by its author.

\section{MARKUSH CLAIMS}

The Guidelines define a "Markush claim" as a patent claim which "consist[s] of a generic chemical structure with multiple alternatives that allow for the protection, under a single patent, of several variants of a claimed invention,"

20. See generally Comm. on Dev. And Intellectual Prop., World Intellectual Prop. Org., Study of Pharmaceutical Patents in Chile 1 n.6 (2012) ("In Brazil, Article 3 of Bill No. H.R. 5402/2013 proposes to explicitly exclude new uses and new forms of existing medicines (including salts, esters, ethers, polymorphs, metabolites, isomers etc.) from what is considered an invention. South Africa's Draft National Policy on Intellectual Property released in 2013 proposes similar provisions.").

21. Working Paper, supra note 2, at vii.

22. Id. at vii-viii.

23. See, e.g., Germán Velásquez, Guidelines on Patentability and Access to Medicines (S. Ctr. Working Paper No. 61, 2015) (citing commentary from parties such as the Minister of Health of Argentina, Secretary-General of Thailand's Food and Drug Administration, and the Minister of Health of Brazil, expressing gratitude, appreciation, and congratulations to the WHO for drafting and publication of the Guidelines).

24. Working Paper, supra note 2, at 3-5. 
often encompassing "several million molecules." ${ }^{25}$ The Working Paper came out strongly against such patent claims, recommending that Markush claims "covering a large range of compounds should not be allowed." 26 This radical recommendation seems to have been based upon a mistaken belief that it would be impossible to perform a prior art search for a claim encompassing so many permutations, with the Working Paper asserting, "Given that a search of prior art for millions of compounds is virtually impossible, the search of the patent office and the corresponding patent grant should be limited to what has been actually assessed and supported by the examples provided in the specification." ${ }^{27}$

In fact, such searches are performed routinely; it is part of the job description of a patent examiner working in the area of pharmaceutical chemistry. A Markush claim is defined by a central structural core, and it is possible for a patent examiner to use a chemical search tool to search for any molecules in the prior art that include that central core. ${ }^{28}$ If none can be found, it can be concluded that the prior art does not encompass the large genus of molecules sharing that common core. ${ }^{29}$ Alternatively, if there are some molecules in the prior art that have that core, they can be identified in the search and the examiner can assess whether the Markush group defined by the claim includes any members that overlap with this prior art. ${ }^{30}$ In short, this alleged inability of patent examiners to perform adequate prior art search with Markush claims simply does not acknowledge the existence of chemical search tools that are available and used every day by patent examiners.

The author of the Guidelines apparently became aware of these tools after publication of the Working Paper, and added a couple of sentences in the Guidelines acknowledging their existence. ${ }^{31}$ But the Guidelines maintain that these tools "do not permit a complete and accurate assessment," and assert that "[s]everal computer-based tools may be required for a comprehensive retrieval, but their use is complex and they do not guarantee accurate results." ${ }^{32}$ Somewhat surprisingly, the Guidelines still retain the original language asserting that it is "virtually impossible to make prior art searches to establish novelty and inventive step for thousands or millions of compounds," but at least the document has dropped the Working Paper's recommendation that would have barred patent protection for any claim covering a "large range of compounds." ${ }^{33}$ Significantly, the Guidelines do not provide any evidence supporting their assertion that chemical search tools "do not permit a complete and accurate assessment" of the prior art, nor do they explain why a patent examiner with expertise in chemistry

25. Guidelines, supra note 1 , at 21.

26. Id. at 12 .

27. Working Paper, supra note 2, at 13.

28. Id. at 12-14.

29. Id. at 13 .

30. $I d$.

31. Guidelines, supra note 1, at 21-22.

32. Id. at 21 .

33. Id. 
would not be expected to be able to effectively use "complex" computer-based tools. ${ }^{34}$

In any event, the Guidelines maintain that the "coverage of the patent should be limited to the claimed embodiments that are actually enabled by the disclosure in the specification, ${ }^{, 35}$ implying that the Guidelines would accept the patentability of a Markush claim if all constituents covered by the claim are "actually enabled." This recommendation might be fine, and entirely consistent with the current standard, depending upon what the author of the Guidelines means by the term "actually enabled." 36 Under U.S. law, a claim is only valid if it is "enabled" (in the legal sense) across its full scope, and this would apply to Markush claims as much as to any other claim. ${ }^{37}$ However, there is no requirement under U.S. law that an inventor has actually synthesized and characterized each and every molecule falling within the scope of the claim. ${ }^{38}$ So long as the inventor has provided sufficient disclosure that would enable one of skill in the art to make and use the full scope of the invention without engaging in undue instrumentation, it is possible for a claim to be enabled even though it covers thousands or even millions of compounds, the vast majority of which have never been synthesized. ${ }^{39}$

The rationale behind this longstanding practice is that there is a certain degree of predictability in chemistry, and certain substitutions at various sites of a relatively complex core molecular structure can be predicted to result in a molecule that retains the utility of other molecules in the genus that have been synthesized and tested. ${ }^{40}$ Given this predictability, there can be a relatively high likelihood that many of the molecules in a claimed genus will share this activity. If an inventor was only permitted to patent molecules that had actually been synthesized and tested, the patent claims would be quite narrow and in many cases quite easy to circumvent. Someone could simply use the disclosure of the patent as a template for designing and synthesizing unpatented analogs sharing the pharmaceutical utility of the claimed molecules. ${ }^{41}$ A genus claim encompassing these variations prevents this sort of easy circumvention by a copyist.

Although a million compounds sounds like a lot, it must be recognized that when there are multiple sites for substitution on a complex molecule, and multiple possible substitutions at each of the sites, the number of possibilities grows exponentially. For example, if there are ten sites of substitution, and ten possible

34. Id.

35. Id. at 23 .

36. Id.

37. 35 U.S.C. $\S 112$ (2012); see also Guidelines, supra note 1, at 21-22.

38. Guidelines, supra note 1, at 17, 21-23.

39. Id.

40. Id. at 23,31 .

41. See generally Christopher M. Holman, Protein Similarity Score: A Simplified Version of the BLAST Score as a Superior Alternative to Percent Identity for Claiming Genuses of Related Protein Sequences, 21 Santa Clara Computer \& High Tech. L.J. 55 (2004). 
substituents at each of the sites, then there are ten to the 10th power, or 10 billion possible drugs that share the same core as the molecules that have been tested and found to be pharmaceutically active. Of course, it is impossible for an inventor to actually synthesize and test anything approaching this number of compounds, but if she is not allowed to obtain a claim encompassing them, a copyist can easily circumvent a narrow patent and develop an analogous molecule to compete with the original inventor. The Guidelines seem to totally disregard the valid policy basis behind the allowance of Markush claims. ${ }^{42}$

In some cases, some of the members of a Markush group will be found not to share the pharmaceutical characteristics that provide the utility basis for patentability of the group as a whole. ${ }^{43}$ But assuming there is a substantial percentage that do have the useful characteristic, then anyone interested in taking advantage of the benefit of the invention can choose to use one of these functional species. ${ }^{44}$ As long as one of skill in the art can readily access constituents of the genus sharing the desired functional characteristics, without engaging in undue experimentation, there should be no policy concern associated with the claim encompassing some constituents lacking utility.

\section{Selection Patents}

The Guidelines define a "selection patent" as a patent claiming

a subgroup of elements ... selected from a larger group and claimed on the grounds that a new, unexpected property has been found. For instance, if a Markush claim was admitted in relation to a set of pharmaceutical compounds, the patent owner might later file a new patent application covering one or more of such compounds. ${ }^{45}$

The Guidelines recommend that selection patents should not be granted, asserting that the "selection of elements included in the disclosed group lacks novelty, such as in the case of compounds disclosed in a prior generic chemical structure or included within a numerical range." 46

The Working Paper proposed a less absolute prohibition against selection patents, recommending,

As a general rule, selection patents should not be granted if the selected components have already been disclosed or claimed and, hence, lack novelty. If unexpected advantages of existing products were deemed patentable under the applicable law, the patentability of a selection could be considered when inventive step is present. ${ }^{47}$

42. Guidelines, supra note 1, at 21-23.

43. Id.

44. Id.

45. Id. at 23 .

46. $I d$. at 25 .

47. Working Paper, supra note 2, at 15. 
The Guidelines correctly observe that the European Patent Office

("EPO") has long taken the position that disclosure of a genus of structurallyrelated molecules does not necessarily anticipate or render obvious all of the molecules formally encompassed by the genus. ${ }^{48}$ For example, in a 1984 decision, a Technical Board of Appeals explained,

[A] strict distinction must be drawn between th[e] purely intellectual content of [a generic disclosure and its] information content in the sense of a specific teaching with regard to technical action. ... When the teaching from a citation is interpreted, special attention must be paid to the material actually disclosed in the sense of a complete, specific technical rule. A group of compounds in which the substituent is characterised by a range teaches the skilled person only about the individuals specifically designated from the group. ${ }^{49}$

Subsequent EPO board decisions have cited this case with approval, and likewise held that disclosure of a chemical entity within a group of substances of known formula is not in itself prejudicial to novelty, but rather that "an individualised description is needed." 50

In contrast, the Guidelines suggest that other jurisdictions apply different criteria in the examination of selection patents. ${ }^{51}$ In fact, a closer look at the cases cited by the Guidelines reveals that none of them support the radical recommendation that selection patents per se should be disallowed for lack of novelty.

The Guidelines begin by claiming that "[i]n Germany, the novelty standard has been strictly applied, leading to the rejection of patentability of selections. The disclosure of a group of compounds, even if large, has been deemed to destroy the novelty of each component of the group." ${ }^{, 52}$

The Guidelines point to a single German decision in support of this assertion, the Federal Supreme Court's 1999 decision in Inkrustierungsinhibitoren.$^{53}$ But the Guidelines completely ignore subsequent developments in German law, most notably the Federal Supreme Court's 2008 decision in Olanzapin that upheld the validity of a selection patent, in spite of the fact that the claimed compound was generically disclosed in the prior art. ${ }^{54}$ Olanzapine is a drug for the treatment of

48. Guidelines, supra note 1 , at 16.

49. Case T 0181/82, "Spiro compounds" (28 Feb. 1984), OJ EPO 1984, 401.

50. Case T 0296/87, “Enantiomers” (Aug. 30, 1988), OJ EPO 1990, 195.

51. Guidelines, supra note 1 , at 25.

52. $I d$. at 24 .

53. The Guidelines do not provide a citation for the case, but are presumably referencing the Federal Supreme Court's decision, Inkrustierungsinhibitoren. Bundesgerichtshof [BGH] Dec. 7, 1999, X ZR 40/95, https://www.jurion.de/urteile/bgh/1999-12-07/x-zr-40_95/.

54. See, e.g., Int'L Ass'N for the Prot. of Intellectual Prop., SElection InVEntionsThe Inventive Step Requirement, Other PAtentability Criteria AND SCOPE OF Protection 3 (2009), https://aippi.org/download/commitees/209/GR209germany.pdf[https://perma.cc/UP7N- 
schizophrenia marketed by Eli Lilly under the trademark Zyprexa. ${ }^{55}$ In Olanzapin, the German court clarified that, as a general matter, a generic structural formula does not constitute disclosure as such of the single compounds covered by that structural formula. ${ }^{56}$ In order for a single compound to be disclosed by a generic structure, the disclosure must enable the person skilled in the art to "get the substance in the hands," which would generally require further information for the "individualisation" of that single compound ${ }^{57}$ The Federal Supreme Court stated that it regarded its decision in Olanzapin concerning chemical formulas to be in line with the EPO's case law (e.g., EPO case T940/98, "Diastereomere" (Feb. 19, 2003)), according to which the only technical teachings that destroy novelty are those that disclose a substance as an inevitable result of a described method or in specified, individualised form. ${ }^{58}$

The Guidelines go on to acknowledge that in the United Kingdom selection patents are valid so long as the selection satisfies the inventive step requirement. ${ }^{59}$ This is correct. In the United Kingdom, for example, a court of appeals upheld a patent on olanzapine even though the prior art disclosed a generic structure encompassing the drug. ${ }^{60}$ The U.K. court observed that "logic dictates rejection of the argument that a disclosure of a large class is a disclosure of each and every member of it," as did EPO case law (see T 296/87, which effectively sums up earlier cases). ${ }^{61}$

A Norwegian court likewise upheld the validity of a patent directed toward olanzapine, noting that nothing in the prior art would have suggested that olanzapine would treat schizophrenia while causing substantially less severe side effects than known treatments, and that the commercial success of Zyprexa provided a strong indication that the solution was not obvious. ${ }^{62}$ Courts in Austria and Germany ruled similarly, with the Austrian court noting the unexpected and surprisingly high effectiveness of olanzapine compared with prior art drugs, including: (1) potential suitability as a neuroleptic, even in small doses; (2) no extrapyramidal side-effects; (3) no agranulocytosis; and (4) fewer instances of elevated liver enzymes. ${ }^{63}$ In the United States, the Federal Circuit also affirmed

$7 \mathrm{KZK}]$.

55. Zyprexa 2.5mg, 5mg, 7.5mg, 10mg, $15 \mathrm{mg}$, and $20 \mathrm{mg}$ Coated Tablets. Zyprexa Velotab $5 \mathrm{mg}, 10 \mathrm{mg}, 15 \mathrm{mg}$, and 20mg Orodispersible Tablets, EMC, https://www.medicines.org.uk/emc/ medicine/614 [https://perma.cc/VVP7-3KGV] (last updated Mar. 9, 2017).

56. InT'L ASS'N FOR the Prot. OF INTELLECtUAL Prop., supra note 54, at 2.

57. Id.

58. Id. at 2-3.

59. Guidelines, supra note 1, at 14-15.

60. Dr. Reddy's Laboratories (UK) Ltd v. Eli Lilly and Co. Ltd [2009] EWCA (Civ) 1362, [2010] RPC 9 (Eng.), http://www.bailii.org/ew/cases/EWCA/Civ/2009/1362.html [https://perma.cc/ B7E6-3LDR].

61. Id.

62. Oslo District Court (Tingrett) of 2 December 2008-Actavis Norway AS v Eli Lilly and Co. Ltd.

63. See, e.g., European Patents Subject to Litigation in Multiple Jurisdictions, EuropeAN 
the validity of the corresponding U.S. patents on olanzapine. ${ }^{64}$

The only other "evidence" cited by the Guidelines in support of its assertion that some jurisdictions categorically treat selection patents as invalid was the Supreme Court of India's 2013 decision in Novartis AG v. Union of India ${ }^{65}$ But this decision does not have anything to do with the novelty or nonobviousness of a selection patent. The Court specifically noted that the IPAB decision below had held that the invention at issue in the case "satisfied the tests of novelty and nonobviousness." Although the Court in Novartis AG found the claims at issue invalid under India's unique Section 3(d) requirement of enhanced efficacy ${ }^{67}$ the decision clearly left open the possibility of patent protection for a selection invention that satisfies the Section 3(d) standard.

As discussed above, a Markush group claimed or disclosed in a prior art patent can encompass millions or even billions of molecules.$^{68}$ However, the mere fact that a generic description of a common structural core with multiple substitution sites can encompass so many molecules should not render each of those molecules unpatentable; particularly a molecule that the prior art generic disclosure does not particularly point out, and which has never actually been made or tested. In the pharmaceutical arts, the physiological and therapeutic effect of a chemical on the body can be predicted based on chemical structure but can only be confirmed by actual testing. Until a compound has been made and actually tested, there is no way to know exactly how it will function. A broad Markush claim encompassing a billion compounds might be fully enabled, in that a large number of those compounds share a common functionality with those molecules that were actually synthesized and tested. But amongst this large group, there could be some molecules with unexpected properties, and if a pharmaceutical researcher perseveres and actually synthesizes and tests a molecule and discovers these unexpected properties for the first time, the existence of the earlier generic disclosure in a prior art patent should not prevent this inventor from getting a patent. Particularly, since without a patent on this new molecule, there will be no incentive to develop it into a drug, especially if the earlier prior art patent is owned by another company, or will expire shortly.

An example of this can be seen in In re Baird, a U.S. case involving the pharmaceutical active ingredient bisphenol A. ${ }^{69}$ It was beyond dispute that the prior art disclosed a generic diphenyl formula which encompassed bisphenol A, a situation the Guidelines would characterize as anticipation rendering the claim invalid. ${ }^{70}$ However, the Federal Circuit upheld the validity of a later patent

PAt. OfF. (Mar. 20, 2015), https://www.epo.org/law-practice/legal-texts/official-journal/2015/ etc/se2/p132.html [https://perma.cc/3R34-BSWJ].

64. Eli Lilly \& Co. v. Zenith Goldline Pharm., Inc., 471 F.3d 1369, 1375 (Fed. Cir. 2006).

65. (2013) SCR 1 (India).

66. Id. at 10 .

67. Id. at 88-89.

68. See supra Part I.

69. In re Baird, 16 F.3d 380, 382-83 (Fed. Cir. 1994).

70. Id. 
directed toward bisphenol A, finding the prior art generic disclosure of a large genus encompassing the patented compound did not render it anticipated or obvious. $^{71}$

In Baird the Federal Circuit began by citing to an earlier decision of the court, In re Jones, in which the Federal Circuit rejected the USPTO's argument that "regardless ... how broad, a disclosure of a chemical genus renders obvious any species that happens to fall within it," and held instead that while in that case the prior art did disclose a genus which encompassed the claimed salt, this prior art reference encompassed a "potentially infinite genus" of salts and thus, for the purpose of patentability of the claimed salt, "did not disclose or suggest the claimed salt." ${ }^{, 2}$

Similarly, the generic diphenyl formula disclosed by the prior art before the court in Baird contained a large number of variables, which the court estimated would encompass more than 100 million different diphenyls, only one of which was bisphenol $\mathrm{A} .{ }^{73}$ The court noted there was nothing in the disclosure suggesting the selection of the particular variables that would result in bisphenol $\mathrm{A} .{ }^{74}$ To the contrary, the court found the prior art taught a preference for a variety of other diphenols encompassed by the prior art genus, thus "teach[ing] away from the selection of bisphenol A by focusing on more complex diphenols."

\section{POLYMORPHS}

The Guidelines state that polymorphism, defined as "the ability of the chemical molecules or ions to exist with different internal crystal structures, ${ }^{76 ،}$ "is an inherent property of a substance, hence polymorphs are not created but found." $" 77$ Obtaining a polymorph is characterized as a "routine activity in pharmaceutical production, carried out through methods widely known to a person skilled in the art," and the Guidelines recommend that "patents on polymorphs should be denied on the grounds of absence of a patentable invention or inventive activity." ${ }^{, 7}$ This radical recommendation marks a significant departure from the Working Paper, which had merely recommended that "[p]atent offices should be aware of the possible unjustified extension of the term of protection arising from the successive patenting of the active ingredient and its polymorphs." ${ }^{\text {"79 }}$ The Guidelines do acknowledge that "a process used for the preparation of a polymorph, if novel and involving inventive step, may be

71. Id.

72. Id. (quoting and citing In re Jones, 958 F.2d 347, 350 (Fed. Cir. 1992)).

73. Baird, 16 F.3d at 382.

74. Id. at $382-83$.

75. Id. at 382 .

76. Guidelines, supra note 1 , at 25.

77. Id.

78. Id. at 27.

79. Working Paper, supra note 2, at 11 . 
patentable." 80

The Working Paper acknowledged that different polymorphs of a drug can have substantially different functional characteristics, and that changing the polymorphic form of a drug active ingredient can result in effects such as altered bioavailability, or a change in long-term stability profile. ${ }^{81}$ But it then proceeded to reach the seemingly inconsistent conclusion that "there is no question of an effect on safety or efficacy [in choosing a particular polymorph], since the active ingredient is the same." ${ }^{82}$ But this is a flawed conclusion-characteristics such as bioavailability do affect the efficacy of a drug, since in order for a drug to have effect it must be made available to the patient.

An example of this can be seen in the case of cefuroxime, a cephalosporin antibiotic discussed later in this Article. ${ }^{83}$ While preparation of an ester derivative did improve bioabsorption, the bioavailability was still relatively low, with a need for further improvement. ${ }^{84}$ Glaxo scientists persevered and found that by changing to a different polymorph, they could provide a product with sufficient bioabsorption for oral administration, resulting in the drug ceftin. ${ }^{85}$ In particular, they found going from a crystalline structure to a highly pure amorphous form allows for a product with superior bioavailability and stability compared to crystalline forms of the drug. ${ }^{86}$

In Glaxo Group Ltd. v. Apotex, Inc., the Federal Circuit rejected a generic company's argument that a patent on the cefuroxime polymorph, U.S. Patent Number 4,562,181 (the '181 patent), was invalid for obviousness. ${ }^{87}$ The challenger argued this patent on the highly pure amorphous form of the drug was obvious in view of an earlier Glaxo patent (the ' 320 patent) that disclosed the same active ingredient, cefuroxime axetil (hereinafter " $\mathrm{CA}$ "), in the forms of (1) an impure amorphous compound and (2) a purer crystalline compound. ${ }^{88}$ Crystalline compounds are those having a structure in which molecules are arranged in a regularly repeating order. ${ }^{89}$ By contrast, the term "amorphous" refers to a structure where molecules are randomly distributed with respect to one another, essentially the opposite of crystalline. ${ }^{90}$ On appeal, the Federal Circuit affirmed a district court's holding that the ' 320 patent did not render the ' 181 patent invalid for obviousness. ${ }^{91}$ In particular, the court found the " 320 patent does not suggest that highly pure amorphous CA product would have better

80. Guidelines, supra note 1 , at 9.

81. Working Paper, supra note 2, at 10-11.

82. Id. at 10 .

83. See infra Part VI.

84. See id.

85. See id.

86. See id.

87. 376 F.3d 1339, 1342-43 (Fed. Cir. 2004).

88. Id. at 1348 .

89. Id.

90. Id. at 1342-43.

91. Id. at 1351. 
bioavailability and stability than a crystalline form. This surprising discovery by Glaxo scientists formed the basis for the issuance of the "181 patent." ${ }^{.92}$ The court found its determination of nonobviousness was supported by a variety of objective indications, including commercial success, long felt but unresolved need, and unexpected results. ${ }^{93}$

The Guidelines suggest the EPO has begun rejecting polymorph patents "as a matter of course," citing a 2011 Technical Board of Appeal decision T 777/08. ${ }^{94}$ However, the Guidelines ignore subsequent decisions, including a 2014 Technical Board of Appeal decision, which found claims directed to polymorphs of Lenvatinib mesylate polymorphs inventive and patentable. ${ }^{95}$ The patent application describes these compounds as being useful as angiogenesis inhibitors, anti-tumor agents, cancer metastasis inhibitors, and as therapeutic agents for treating a range of diseases such as angioma, retinal neovascularisation, diabetic retinopathy, inflammatory disease, and atherosclerosis. ${ }^{96}$ The Board specifically pointed to improved characteristics of the polymorphs such as low hygroscopicity and stability under various conditions of humidity, temperature, and light, noting that these characteristics, even though they do not directly relate to efficacy of the active ingredient, are clearly "[important] in determining the viability of a pharmaceutical salt," and held

in order to fully assess the issue of inventive step, it must be established whether there was any suggestion in the prior art that would have led the skilled person to expect that the subject-matter claimed would provide the present combination of favourable properties, not only in terms of solubility and bioavailability, but also hygroscopicity and stability. ${ }^{97}$

The EPO Board pointed to prior art, cautioning that "the selection of the salt form that exhibits the desired combination of properties remains a difficult semiempirical choice," and showing "improvement in one desired property [in a particular salt form] may be to the detriment of another." ${ }^{98}$ Another prior art reference cited by the Board emphasized that "choosing the appropriate salt . . . [c]an be a very difficult task, since each salt imparts unique properties to the parent compound." $" 99$

Similarly, a Swedish court upheld the inventiveness of a patent directed toward calcipotriol monohydrate in spite of prior art disclosing anhydrous calcipotriol. ${ }^{100}$ The court found the monohydrate polymorph provided unexpected

92. Id. at 1349.

93. Id.

94. Guidelines, supra note 1 , at 26.

95. Case T 0643/12, "Lenvatinib mesylate polymorphs/EISAI" (June 18, 2014).

96. Id. at 5.1 .

97. Id. at 5.4.2.

98. Id.

99. Id.

100. European Patent No. 0679 154, District Court of Stockholm (issued 20 May 2011), Leo $v$ Sandoz (Swed.). 
benefits in terms of suitability for use in pharmaceutical compounds for the production of creams and gels. ${ }^{101}$ At the time of the invention, the court found there was no incentive that would have led an expert to try to produce the monohydrate of calcipotriol as a means to address problems that had been encountered in attempting to formulate creams and gels from the anhydrous form of the drug. ${ }^{102}$ To the contrary, the court found that rather than searching for new crystalline forms of calcipotriol, one who exhibited skill in the art would have been more likely to stay with the anhydrous form and attempt to address the problem by modifying process conditions. ${ }^{103}$

The Guidelines again point to the Supreme Court of India's decision in Novartis $A G,{ }^{104}$ implying that somehow it has some bearing on the patentability of polymorphs in India. As noted above, Novartis $A G$ has nothing to do with novelty or inventiveness, but is limited to a specific application of India's Section 3(d) requirement of enhanced efficacy. The Indian Court's decision in no way supports the Guidelines ' recommendation that patents on polymorphs be denied on the grounds of absence of patentable invention or inventive activity. ${ }^{105}$

To the contrary, the New Delhi Patent Office in India has recognized the inventiveness and patentability of a new polymorph of an existing active ingredient. ${ }^{106}$ In the matter of Application no. 106/DELNP/2008, for example, the claimed invention was new polymorphic form ("form beta") of rifaximin, a known substance. ${ }^{107}$ The drug is useful for treating bowel disorders related to bacterial overgrowth, such as irritable bowel syndrome, Crohn's disease, and colitis. ${ }^{108}$ The inventors had discovered that the claimed polymorphic form beta of the active ingredient is 100 -fold less toxic than the prior art crystalline form, while retaining the full efficacy of the prior art form. ${ }^{109}$ This reduction in toxicity is a result of polymorphic form beta having an in vivo absorption level of about 100 -fold lower than the prior art crystalline form of the drug. ${ }^{110}$

The Indian patent examiner initially rejected the claims for, among other reasons, lack of inventive step, but on appeal the Controller overturned this decision, finding that the claimed invention provides a new form of rifaximin having unexpected properties over the closest prior art. ${ }^{111}$ The Controller found

101. Id.

102. Id.

103. Id.

104. Guidelines, supra note 1 , at 9.

105. See Controller's Decision In the matter of Application no. 106/DELNP/2008, Dec. 26, 2012 (on file with the author.)

106. Id.

107. Id.

108. Id.

109. $I d$.

110. $I d$.

111. Id. This decision was consistent with the decisions of the U.S. and European patent offices, which issued patents on the corresponding applications. See U.S. Patent No 7,045,620 (filed Dec. 5, 2003); European Patent No. 1,676,847 (filed Sept. 3, 2004). 
"it was totally unpredictable what kind of crystalline forms of rifaximin, if any, could exist and how they were to be obtained and distinguished from each other," and further that the prior art provided "no reasonable expectation of success that polymorphic forms of Rifaximin exist at all." 112

The Controller emphasized that "the point is not whether the skilled person could have arrived at the invention by modifying the prior art, but rather, whether in expectation of the advantages actually achieved, he would have done so because of prompting in the prior art." ${ }^{, 13}$ The prior art provided no prompting to arrive at polymorphic form beta of rifaximin, particularly in view of the very specific crystallization conditions necessary to produce this polymorphic form, including the use of specific temperature, crystallization time, and a critical step of washing the solid with water. The Controller found the "negligible absorption of rifaximin $\beta$ was not at all to be expected on the basis of prior art documents," and this dramatic reduction in absorption had rendered it possible to "modulate the pharmacological properties rifaximin by properly selecting the appropriate polymorphic form." 114 In addition, the Controller found the claims to the polymorph "may be set free of the clutches of sec[tion] 3(d)" of the Indian Patent Act, which requires an "enhancement of efficacy" as an independent requirement of patentability for new forms of known substances, including polymorphs. ${ }^{115}$

Courts in Chile and Colombia have also reportedly upheld the validity of patents directed to polymorphs, i.e., polymorphic Form II of clopidogrel hydrogen sulphate and polymorphic Form III of atorvastatin calcium, respectively. ${ }^{116}$

\section{ENANTIOMERS}

The Guidelines recommend that "isolated enantiomers should not be deemed

112. See In the matter of Application no. 106/DELNP/2008.

113. Id.

114. Id.

115. Patents Act, No. 15 of 2005, INDIA CODE (2005), http://www.ipindia.nic.in/writereaddata/ Porta1/IPOAct/1_69_1_patent_2005.pdf[https://perma.cc/DN2H-ZTZE].

116. Lisa L. Mueller, A Global Review of the Patentability of Polymorphs, BRIC WALL BLOG (Aug. 21, 2015), https://bricwallblog.files.wordpress.com/2015/08/polymorphsglobalstudy.pdf [https://perma.cc/N2AA-PLPC] ("[T] he Third Court of Criminal Oral Trial of Santiago de Chile decided in favor of the patent holder Sanofi-Aventis, regarding patent No. 42308, in an infringement action against the commercialization of a medicament comprising the polymorphic Form II of clopidogrel hydrogen sulphate.") ("The case involving Warner-Lambert Company in Colombia is relevant to polymorphs. In this case, an application claiming a new polymorphic form of atorvastatin calcium (Form III) was rejected by the CPO. During a first Reconsideration Procedure, the court confirmed the rejection of the application as lacking inventive step. However, during a Nullity Procedure (case reference No. No. 2003-00256) against the Rejection resolution, a contrary decision was issued as the Andean Court found that the subject matter of the new polymorphic form of atorvastatin calcium (Form III) was inventive as it was non-obvious to a person skilled in the art.”). 
patentable when the racemic mixture was previously disclosed." 117 Once again, this is an even more radical recommendation than was set forth in the Working Paper, which has used the slightly more measured language that "[s]ingle enantiomers should generally not be deemed patentable when the racemic mixture was known." ${ }^{\prime 18}$ Interestingly, the Guidelines do acknowledge the possibility that a new process for obtaining enantiomers might be developed that is novel and inventive, and suggest that such a process might be patentable. ${ }^{119}$ Unfortunately, the Guidelines fail to recognize that sometimes an enantiomer can itself be nonobvious.

An example of this can be seen in the case of Forest Laboratories, Inc. $v$. Ivax Pharmaceuticals, Inc., in which the Federal Circuit concluded that prior art disclosing a racemic mixture did not render a purified enantiomer obvious, because the prior art failed to provide a method for performing the separation that did not require undue experimentation. ${ }^{120}$ The prior art showed that skilled pharmacological chemists had attempted to separate the enantiomeric components of the mixture from one another using a number of state of the art techniques such as chiral High-Performance Liquid Chromatography (HPLC) and diasteromeric salt formation, and that it was only after much experimentation that the inventors discovered a workable method for separating these particular enantiomers. ${ }^{121}$ The extent to which the therapeutic properties of the isolated enantiomer exceeded those of the known racemate also contributed to the Federal Circuit's ultimate conclusion that the enantiomer was nonobvious. ${ }^{122}$

In Sanofi-Synthelabo v. Apotex, Inc., experts testifying for both the patent owner and the patent challenger agreed that, as a general matter, separating enantiomers from one another can be a very technically challenging proposition. ${ }^{123}$ This difficulty arises from the fact that enantiomers share the exact same chemical structure and chemical formula - the only difference between a pair of enantiomers resides in the three-dimensional arrangement of molecular constituents around a single carbon atom in the compounds. ${ }^{124}$ This high degree of similarity makes it very difficult, as a general proposition, to separate the two from each other, since for the most part they tend to have identical physical and chemical properties. ${ }^{125}$ There is no general methodology for separating enantiomer-each separation problem must be solved out on a case-by-case basis, in an unpredictable process of trial and error experimentation.

Furthermore, there is no general expectation that separating a racemate into its constituent enantiomers will provide any benefit. For example, consider the

117. Guidelines, supra note 1 , at 29.

118. Working Paper, supra note 2, at 17.

119. See Guidelines, supra note 1.

120. 501 F.3d 1263 (Fed. Cir. 2007).

121. Id. at $1266-67$.

122. $I d$.

123. 550 F.3d 1075, 1080-81 (Fed. Cir. 2008).

124. $I d$.

125. Id. 
development of Plavix, a drug that inhibits the aggregation of blood platelets and is used to treat or prevent blood-thrombotic events such as heart attacks and strokes. ${ }^{126}$ The active ingredient in Plavix is clopidogrel, which is the dextrorotary isomer (i.e., d-enantiomer) of a chemical compound referred to as MATTPCA. ${ }^{127}$ The Federal Circuit upheld the validity Sanofi's U.S. patent claiming clopidogrel bisulfate in Sanofi-Synthelabo v. Apotex, rejecting the generic company's argument that the enantiomer was obvious. ${ }^{128}$

MATTPCA is a member of a class of molecules known as thienopyridines, and the court found it relevant that prior to the invention of clopidogrel Sanofi scientists had on two occasions tried separating out the enantiomers from racemic mixtures of other thienopyridines, and in both instances found that the separation provided no benefit. ${ }^{129}$ In one case, separation revealed that one of the enantiomers was more biologically active than the racemic mixture, but also more neurotoxic, resulting in no net improvement. ${ }^{130}$ In the other case, separation resulted in enantiomers that were both found to have the same activity as the racemate. ${ }^{131}$ Based on these discouraging results, the Sanofi researchers who led these projects had come to the conclusion that it was not worth the effort to try separating out enantiomers of thienopyridines. ${ }^{132}$

Fortunately, the inventors of clopidogrel bisulfate persevered against this conventional wisdom and decided to try to develop a process for separating out the enantiomers of MATTPCA. ${ }^{133}$ It was not easy. ${ }^{134}$ The chemical literature at the time showed that there were at least ten potential separation techniques they could have tried, but it was impossible to predict which, if any, of these techniques might succeed. ${ }^{135}$ After five months of experimentation, the inventors succeeded in developing a process for separating the enantiomers, and upon testing the enantiomers they discovered that in this case the separation provided a huge pharmaceutical advantage. ${ }^{136}$

In particular, the inventors discovered that the d-enantiomer possessed all of the therapeutic benefit, while the other enantiomer was responsible for nearly all of the adverse side effects, including neurotoxicity. ${ }^{137}$ Experts testifying for both

126. Id. at 1081.

127. See generally id. The full chemical name of MATTPCA is methyl alpha-5(4,5,6,7-tetrahydro(3,2-c)thieno pyridyl)(2-chlorophenyl)-acetate. Id. at 1080. During research and development of the drug, Sanofi scientists referred to MATTPCA as PCR 4099 and, in its decision, the Federal Circuit uses both terms interchangeably. See generally id.

128. Id. at 1090 .

129. Id. at 1081 .

130. Id.

131. Id.

132. Id.

133. Id.

134. Id.

135. Id.

136. Id. at 1082 .

137. Id. at 1081 . 
parties to the litigation agreed that this sort of stereoselectivity is rare and that in most cases pharmaceutical activity and toxicity are positively correlated. ${ }^{138}$ In other words, the enantiomer having the pharmaceutical activity is typically found to be the same one that has the toxicity issues, in which case separation does not provide any net benefit. They also agreed that when stereoselectivity does exist, it is usually weak. ${ }^{139}$ The "absolute stereoselectivity" of MATTPCA's denantiomer could not have been predicted given the failed attempts with other thienopyridines. ${ }^{140}$ Based on this surprising development, Sanofi decided to develop the therapeutic enantiomer rather than the racemate, thus arriving at Plavix, a pharmaceutical with a greatly improved efficacy-safety profile. ${ }^{141}$

Witnesses in the case explained that at the time the enantiomeric drug was being developed, it

was known that for compounds whose biological activity is delivered through metabolism within the body [like MATTPCA], the acid environment in the stomach or other metabolic processes often restores the racemic state, thereby removing any potential benefit of a separated enantiomer. ${ }^{142}$

This knowledge would have further discouraged one of skill in the art from investing substantial time and money into searching for a means of separating the enantiomers and, should they succeed in the separation, characterizing the pharmacologic and toxicity profiles of the purified enantiomers.

Different molecules have different characteristics that can render it more difficult to successfully separate enantiomers, so the inventiveness of any enantiomer has to be evaluated on a case-by-case basis. ${ }^{143}$ It is a mistake to simply assume that the separation of any enantiomer is routine because another enantiomeric separation was straightforward. For example, in Sanofi, the court found one of skill in the art would recognize that it would be particularly difficult to separate the enantiomers of MATTPCA compared with other molecules in the same class, because MATTPCA includes a methyl ester substituent that would make it more susceptible to re-racemization, thus resistant to obtaining a stable separated product. ${ }^{144}$ Specific considerations of this type must be taken into account and factored into the obviousness calculus, something that the blanket recommendation of the Guidelines fails to do. ${ }^{145}$

138. $I d$.

139. Id.

140. Id. at 1087-88.

141. See, e.g., Michel E. Bertrand et al., Double-Blind Study of the Safety of Clopidogrel with and Without a Loading Dose in Combination with Aspirin Compared with Ticlopidine in Combination with Aspirin After Coronary Stenting, CIRCUlATION 624 (2000), http://circ.ahajournals.org/content/102/6/624 [https://perma.cc/6HND-ETFD].

142. Sanofi-Synthelabo, 550 F.3d at 1087.

143. Id. at 1085-89.

144. Id. at 1088 .

145. Id. 
The Sanofi court described the separation of MATTPCA as a paradigm of "trial and error," noting

neither the chemists at Sanofi nor a person of ordinary skill in the art could have reasonably expected that the separate enantiomers of [MATTPCA] could be obtained at the time that Sanofi was contemplating whether to investigate them and, if obtained, they could not have predicted by what method and configuration. ${ }^{146}$

Prior to shifting development investment to clopidogrel, the pharmaceutically active d-enantiomer, Sanofi had spent seven years and tens of millions of dollars seeking to develop the MATTPCA racemic mixture into a drug. ${ }^{147}$ The Federal Circuit found this fact to be relevant to the nonobviousness of clopidogrel bisulfate. ${ }^{148}$ After all, if it was obvious that the enantiomer would likely result in a superior product and isolation of the enantiomer was relatively easy, why would the pharmaceutical company have waited so long and invested so heavily in the racemate?

Courts in Europe have also upheld patents on enantiomers, particularly in cases where the prior art failed to provide a predictable process for achieving the separation. For example, in Generics v. Lundbeck, courts in the United Kingdom upheld a patent directed toward the escitalopram, a selective serotonin reuptake inhibitor ("SSRI") used to alleviate the symptoms of depression. ${ }^{149}$ Escitalopram is an enantiomer of citalopram, marketed in the U.K. under the brand name cipralex. ${ }^{150}$ The court found the "resolution of a racemate by separation into its enantiomers is not a straightforward matter," noting that because they share virtually identical physical characteristics, such as boiling point, conventional separation processes such as fractional distillation and fractional crystallization may not work. ${ }^{151}$ In the case of escitalopram, the court found it had taken seven years of trial and error testing for researchers to discover a way to separate out the enantiomers of citalopram. ${ }^{152}$

Significantly, as noted by the U.K. court, the patent on escitalopram did not prevent a number of manufacturers from selling generic versions of the original racemate drug, citalopram, once it had expired in the U.K. ${ }^{153}$ This is yet another example illustrating the fallacy of the premise that patents on enantiomers

146. Id. (citing Sanofi-Synthelabo, Inc. v. Apotex, Inc., 492 F. Supp. 2d 353, 371 (S.D.N.Y. 2007))

147. Id. at 1081 .

148. Id. at 1087.

149. [2007] EWHC (Pat) 1040; see also Lundbeck v. Generics [2008] EWCA (Civ) 311, http://www.bailii.org/ew/cases/EWCA/Civ/2008/311.html [https://perma.cc/GD33-JNNF].

150. See generally Antidepressant Citalopram Heart Safety Warning, NHS CHOICES (July 2, 2012), http://www.nhs.uk/news/2012/07July/Pages/antidepressant-citalopram-qt-heart-rhythmsafety-warning.aspx [https://perma.cc/CJ8C-X8DN].

151. Lundbeck v. Generics [2008] EWCA (Civ) 311 [3].

152. Id.

153. Id. at [1]. 
somehow provide "evergreened" protection for products whose patents have expired.

Courts in the Netherlands and Germany likewise upheld the nonobviousness of related patents directed toward escitalopram that were challenged in those countries. ${ }^{154}$ The Netherlands court emphasized that even in a case where the composition and possible features of an enantiomer are known, the enantiomer can nonetheless be nonobvious and patentable "if on the priority date the state of the art does not include a method for obtaining th[e] substance." 155 Similarly, the German court observed that obtaining a single enantiomer of a compound so far existing only as a mixture of enantiomers (racemate) might entail an inventive step even if the existence of the enantiomers was rendered obvious by the prior art. ${ }^{156}$ The decisive factor was whether, at the priority date, there was an obvious way for the skilled person to obtain the enantiomer. ${ }^{157}$

In Generics v. Daiichi Pharmaceutical Co., a U.K. court upheld the nonobviousness of a patent directed toward levofloxacin, a chiral antimicrobial compound that is an enantiomer of the racemic drug ofloxacin. ${ }^{158}$ In the lower court's decision, the judge decided the skilled man "would have considered it worthwhile exploring whether ofloxacin could be resolved, but only to a point."159 In view of the difficulty and uncertainty associated with developing a process for separating enantiomers, the court concluded the proposed route would not have been attractive enough to justify pursuit of it, and on appeal the court agreed that this analysis supported a finding of nonobviousness. ${ }^{160}$

The appellate judge in Daiichi included the following observation in his decision upholding the patent on levofloxacin:

I am not sorry to reach this conclusion [of nonobviousness]. Daiichi's work led to a better medicine than ofloxacin. Levofloxacin is not just twice as active as ofloxacin (which might have been expected) but is a lot more soluble and less toxic than was predictable. It can be used in higher dosages than might have been expected with corresponding medical benefit. Only a curmudgeon would say there was no invention here. ${ }^{161}$

A Canadian federal court of appeals also found levofloxacin nonobvious. ${ }^{162}$

In Laboratorios Ranbaxy, S.A. v. Warner-Lambert Co., a Spanish court of

154. See generally HR 7 juni 2013, TT 2013 (Lundbeck/Tiefenbacher) (Neth.); Bundesgerichtshof [BGH] Sept. 10, 2009, Xa ZR 130/07.

155. See HR 7 juni 2013, TT 2013 (Lundbeck/Tiefenbacher) (Neth.) at 4.3.

156. Bundesgerichtshof [BGH] Sept. 10, 2009, Xa ZR 130/07.

157. Id.

158. See generally [2009] EWCA (Civ) 646, http://www.bailii.org/ew/cases/EWCA/Civ/ 2009/646.html [https://perma.cc/6HRH-6YSB].

159. Id. at [16].

160. Id. at [10], [44]-[45].

161. Id. at [45].

162. Novopharm Ltd. v. Janssen-Ortho Inc., [2007] F.C.A. 217 (Can.), http://decisions.fctcf.gc.ca/fca-caf/decisions/en/item/35631/index.do [https://perma.cc/9AUL-MLUH]. 
appeals upheld the nonobviousness of a patent claiming the calcium salt of enantiopure atorvastatin. ${ }^{163}$ The court observed "that it was not enough that the average person skilled in the art could or might have opted for the solution proposed by the applicant for the patent; rather what mattered was that he actually would have made that choice." 164

\section{SALTS}

The Guidelines recommend that "[p]atent applications on particular salts will normally face an objection of lack of inventive step." ${ }^{165}$ The Guidelines acknowledge "[t]he choice of a salt for a particular drug is important in obtaining certain desirable characteristics related to stability, bioavailability, manufacturability and route of administration to the patient." ${ }^{166}$ However, the Guidelines assert that the "preparation of salts, [even those] with advantageous properties over the drug in its free base/acid form, is part of the common knowledge of a person skilled in the art." $" 167$

The Working Paper took a slightly less stringent position, acknowledging that under certain circumstances this presumption of unpatentability should not apply, particularly when the patent specification describes "appropriately conducted [tests demonstrating] unexpected advantages in properties as compared to what was in the prior art." 168

The Guidelines assert that "[i]t has been common in the pharmaceutical industry to file patent applications on particular salts as a means of evergreening. ${ }^{, 169}$ But patents on particular salt forms of a drug are generally quite narrow, limited to that particular salt form. ${ }^{170}$ There are many different potential salts that can be made of a drug, and if it is easy to find another one that works (as is apparently assumed by the Guidelines), then a competitor can avoid the patent by simply using another salt. ${ }^{171}$ In contrast, if there is real value and differentiation in the particular salt that is claimed, then why should the inventor who invested in developing it not be allowed a narrow patent limited to that particular salt form? As leading patent-authority Judge Giles Rich put it, "[a] monopoly on something nobody wants is pretty much ... a nullity. That is one

163. Summary provided at Special Edition 3 of OJ EPO 1, 17 (2011), http://www.cyberepc. com/fileadmin/upload/Jurisp_Etats_Mb/2004_2011/Appreciation_de_1_activite_inventive.pdf [https://perma.cc/MEY8-MMUP].

164. Id.

165. Guidelines, supra note 1 , at 9.

166. Id. at 30 .

167. Id. at 32 .

168. Working Paper, supra note 2, at 10.

169. Guidelines, supra note 1 , at 30.

170. Id. at 29-30.

171. See, e.g., Sanofi-Synthelabo, Inc. v. Apotex, Inc., 550 F.3d 1075, 1088-89 (Fed. Cir. 2008) (stating "the scientific literature listed eighty acids as candidates for forming salts with basic drug compounds"). 
of the beauties of the patent system. The reward is measured automatically by the popularity of the contribution." 172

Significantly, a generic company seeking to sell a competing version of an active ingredient whose patent has expired is free to do that, so long as they do not use the particular salt form that is patented. ${ }^{173}$ In the U.S., for example, there are two pathways for obtaining approval for follow-on drug products under sections 505(b)(2) and 505(j), respectively, of the Federal Food, Drug, and Cosmetic Act. ${ }^{174}$ Although generic companies typically rely on the Section 505(j) abbreviated new drug application (ANDA), Section 505(b)(2) provides an alternative mechanism for seeking approval to market a modified but nonetheless bioequivalent formulation, such as a different and unpatented salt form. ${ }^{175}$

According to the Guidelines, "If an active ingredient is an acid or base, then any chemistry student knows how to make a salt, and can make predictions about its likely physicochemical properties." no evidence or support for this conclusory assertion, an assertion that goes entirely against the consensus view among pharmaceutical chemists. According to this consensus, in most cases it is impossible to accurately predict the physicochemical properties of a new salt form of a drug, regardless of how well characterized the particular counterion is when paired with other drug active ingredients. ${ }^{177}$ As noted by Judge Newman of the Federal Circuit, when it comes to biological and medicinal products, "small change[s] can produce large differences." 178 In her dissent to the majority's decision in Pfizer v. Apotex, Judge Newman pointed out that in that case, involving a patent directed toward the besylate salt of amlodipine, the parties on both sides stipulated to the fact that "one of ordinary skill in the art could neither draw any conclusions nor have any expectations about the properties of amlodipine besylate from the properties of a besylate salt of a different compound." 179

Oftentimes, the benefits of a particular salt form reside not in therapeutic effect but in other properties that nonetheless contribute substantial value to the product and, ultimately, patients. ${ }^{180}$ For example, in Pfizer v. Apotex, the prior art salts of amplodipine were plagued by a number of undesirable properties that stood in the way of creating an optimized product, such as stickiness, instability, low solubility and hygroscopicity, but these deficiencies were unexpectedly solved by development of the besylate salt of the drug. ${ }^{181}$ Judge Newman pointed

172. Giles S. Rich, Principles of Patentability, 28 GEO. WASH. L. REV. 393, 402 (1960).

173. Guidelines, supra note 1 , at 6, 9-10.

174. 21 U.S.C. $\S \S 355(b)(2), 355(j)(2012)$.

175. See, e.g., Pfizer Inc. v. Dr. Reddy's Labs., Ltd., 359 F.3d 1361, 1364 (Fed. Cir. 2004).

176. Guidelines, supra note 1 , at 9.

177. Pfizer, Inc. v. Apotex, Inc., 488 F.3d 1377, 1379 (Fed. Cir. 2007) (Newman, J., dissenting).

178. Id.

179. Id.

180. Id. at 1382 .

181. Id. 
out that, in view of the complexity of interaction between drug active ingredients and a salt counterion, pharmaceutical chemists must usually accept some undesirable properties to achieve other desirable ones. ${ }^{182}$ The patented invention, amlodipine besylate, presented none of the trade-offs associated with other amlodipine salts that were tested. ${ }^{183}$ It would be a mistake to disregard these nontherapeutic values in an assessment of obviousness. As noted by the Federal Circuit's Judge Lourie, a chemist by training with experience in the pharmaceutical industry, ${ }^{184}$ it would not be sound policy to require an improvement in therapeutic properties over the prior art as a requirement of patentability and to negate the importance of other physical properties of a claimed compound or salt. ${ }^{185}$

A review article on pharmaceutical salts written by a group of scientists from academia and industry has noted that

[s]alt-forming agents are often chosen empirically .... Unfortunately, there is no reliable way of predicting the influence of a particular salt species on the behavior of the parent compound. Furthermore, even after many salts of the same basic agent have been prepared, no efficient screening techniques exist to facilitate selection of the salt most likely to exhibit the desired pharmacokinetics, solubility, and formulation profiles. ${ }^{186}$

As noted by another Federal Circuit panel in Pfizer Inc. v. Ranbaxy Laboratories, "Given the unique properties each salt imparts to the parent compound, salt selection is not a routine process and the success of a given salt is not easily predicted." 187 The Pfizer court found the prior art presented in that case, involving a patent on the calcium salt of atorvastatin, "suggest[ed] that the selection of salts is a difficult task." 188

In Sanofi, the Federal Circuit decision finding a patent on the bisulfate salt of the d-enantiomer of MATTPCA (the active ingredient in Plavix) to be nonobvious, the court credited the testimony of an expert for the generic company who agreed that salt formation was an unpredictable exercise that would require a chemist "to engage in experimentation to determine which salt would in fact be suitable." 189 In that case, the circuit court upheld the district court's determination that the prior art did not render it obvious to prepare and test the bisulfate salt of

182. Id. at 1379 .

183. Id. at 1380 .

184. Alan D. Lourie, Circuit Judge, U.S. CT. ApPeAls FOR Fed. CiR., http://www.cafc. uscourts.gov/judges/alan-d-lourie-circuit-judge [https://perma.cc/HYH3-FSR6] (last visited Mar. $23,2017)$.

185. Apotex, 488 F.3d at 1382 (Lourie, J., dissenting).

186. Stephen M. Berge et al., Pharmaceutical Salts, 66 J. Pharmaceutical Sci. 1, 1 (1977).

187. 405 F. Supp. 2d 495, 501, 517 (D. Del. 2005), rev'd on other grounds, 457 F.3d 1284 (Fed. Cir. 2006).

188. Id. at 517 .

189. Sanofi-Synthelabo, Inc. v. Apotex, Inc., 470 F.3d 1368, 1379 (Fed. Cir. 2006). 
clopidogrel, particularly in light of the fact that the inventors had to engage in extensive experimentation before arriving at that particular compound, which involved the testing of twenty different salts before discovering that the bisulfate had the most desirable properties. ${ }^{190}$

Pfizer, Inc. v Mylan Laboratories, Inc. provides yet another example of a case in which the unpredictability of salt selection was found to be a factor supporting the patentability of a specific salt form. ${ }^{191}$

\section{ETHERS AND ESTERS}

The Guidelines acknowledge that ester and ether derivatives of pharmaceutical products can exhibit improved safety or efficacy, but for some reason concludes that "they would not generally enhance the therapeutic efficacy of a drug." $" 192$ The Guidelines essentially treat ethers and esters in the same manner as salts, finding that their preparation is part of the common knowledge of a person skilled in pharmaceuticals, and therefore obvious. ${ }^{193}$ As with salts, the Guidelines recommend that "[p]atent applications on particular ethers and esters will normally lack [an] inventive step.",194

In fact, the ester or ether derivative of an active ingredient can have unexpected and highly valuable clinical advantages compared with the base compound, and should not be considered lacking in invention and ineligible for patent protection. An example of this can be seen in the case of the antibiotic cefuroxime, a member of the cephalosporin family, and the subject of U.S. Patent Number 3,974,153. ${ }^{195}$ Glaxo developed cefuroxime in the 1970s, but because of the compound's poor bioabsorption characteristics it needed to be administered by intravenous or intramuscular injection, severely limiting its usefulness as an antibiotic. ${ }^{196}$ Glaxo scientists persevered and ultimately developed a family of cefuroxime esters that had improved bioabsorption, which allowed for oral administration. ${ }^{197}$ This ester was the subject of two patents, U.S. Patent Numbers $4,267,320$ and 4,562,181, and these patents provided the necessary incentive for the development of these important orally administered drugs, sold under the trade name Ceftin. ${ }^{198}$

Without the availability of patents for esters, these oral antibiotics likely

190. Id.

191. No. 02-1628, 2007 WL 654274, at*30 (W.D. Pa. Feb. 27, 2007). Although the trial court sided with Pfizer, the decision was ultimately reversed after the ruling in Pfizer Inc. v. Apotex, Inc., 488 F.3d 1348 (Fed. Cir. 2007), which held Pfizer's patent invalid. Pfizer, Inc. v. Mylan Labs., Inc., No. 2007-1194, 2007 WL 1662640, at*1 (Fed. Cir. June 5, 2007).

192. Guidelines, supra note 1 , at 32 .

193. See id. at $29,32$.

194. Id. at 34 .

195. Glaxo Grp., Ltd. v. Apotex, Inc., 376 F.3d 1339, 1342 (Fed. Cir. 2004).

196. Id.

197. Id. at $1342-43$.

198. Id. 
would never have been developed. Today the world faces a crisis of insufficient antibiotics because many pathogenic microorganisms are becoming antibiotic resistant. ${ }^{199}$ Part of the reason for the dearth of antibiotics is insufficient incentives for their development. ${ }^{200}$ It would be a mistake to deny patents for esters and other allegedly obvious variants of active ingredients, because this would only serve to dampen further the incentive for their development.

\section{COMPOSITIONS}

The Guidelines recommend "[ $t$ ]he preparation of pharmaceutical compositions (formulations) requires the use of techniques and compounds commonly known to a person skilled in that field. Patent applications on compositions will normally confront an objection of lack of inventive step." ${ }^{201}$ Similarly, the Working Paper recommended that "[n]ew formulations and compositions, as well as processes for their preparation, should generally be deemed obvious in the light of the prior art, particularly when a single active ingredient is claimed in association with known or unspecified carriers or excipients. ${ }^{202}$ The Working Paper acknowledged the relatively limited scope of the claims and the consequent relatively minor impediment to competition created by such patents. ${ }^{203}$ In particular, the Working Paper noted that such patents do not protect the active ingredient per se, and competing companies are thus free to commercialize different formulations or compositions comprising the same ingredients. ${ }^{204}$

The Guidelines fail to take into account the extremely large number of potential reformulations that are possible, and the sometimes-dramatic improvements in safety and efficacy that can be achieved by an innovative new formulation of an existing drug. An example of benefits flowing from the research and development of new formulations can be seen in the case of Lumigan, a drug used to treat glaucoma ${ }^{205}$ Glaucoma is an eye disease associated with elevated intraocular pressure ("IOP"), which if left untreated can lead to permanent vision loss and blindness. ${ }^{206}$ Treatment with Lumigan effectively reduces IOP and can slow the progression of the disease. ${ }^{207}$ Unfortunately, the

199. See, e.g., Melinda Wenner Moyer, Dangerous New Antibiotic-Resistant Bacteria Reach U.S., SCI. AM. (May 26, 2016), https://www.scientificamerican.com/article/dangerous-newantibiotic-resistant-bacteria-reach-u-s/ [https://perma.cc/X7KG-TA8K].

200. See Ezekiel J. Emanuel, How to Develop New Antibiotics, N.Y. Times (Feb. 24, 2015) https://www.nytimes.com/2015/02/24/opinion/how-to-develop-new-antibiotics.html?_r=0 [https://perma.cc/B84X-5G3T].

201. $I d$.

202. Working Paper, supra note 2, at 7.

203. Id. at 6-7.

204. Id. at 6 .

205. Allergan, Inc. v. Sandoz, Inc., 796 F.3d 1293, 1298 (Fed. Cir. 2015).

206. $I d$.

207. Id. 
original formulation of Lumigan, approved by the U.S. Food and Drug Administration ("FDA") in 2001, had a tendency to cause severe hyperemia (i.e., red eye), and for that reason patients would often discontinue use of the drug without consulting their physicians, which sometimes led to blindness. ${ }^{208} \mathrm{Clearly}$, there was a need for an improved formulation that would reduce the adverse side effect and thereby improve patient compliance. Fortunately, the incentive of patent protection was available to spur further research, which ultimately led scientists at the company that marketed Lumigan to develop an improved formulation having a substantially reduced tendency to cause hyperemia. ${ }^{209}$

On its face, the change in formulation might seem relatively straightforward, and some might go so far as to characterize it as obvious and unworthy of patent protection. The original formulation, Lumigan $0.03 \%$, contained $0.03 \%$ by weight of bimatoprost (the active ingredient) and fifty parts per million ("ppm") benzalkonium chloride ("BAK"), among other ingredients. ${ }^{210}$ BAK is a preservative used to inhibit bacterial growth in ophthalmic solutions. ${ }^{211}$ Pharmaceutical chemists knew, however, that BAK is cytotoxic and that it can damage the cells on the ocular surface and cause undesirable side effects. ${ }^{212}$

Allergan, the company that developed the original $0.03 \%$ formulation of Lumigan, invested in research to identify some means for reducing the drugs adverse side effects while maintaining therapeutic efficacy. ${ }^{213}$ After exploring several alternative formulations of the active ingredient, Allergan scientists discovered that the corneal permeability of bimatoprost could be significantly increased by raising the concentration of BAK from fifty ppm to $200 \mathrm{ppm} .{ }^{214}$ This change in formulation allowed for the use of a significantly lower concentration of bimatoprost $(0.01 \%)$ to achieve an efficacy similar to that of the $0.03 \%$ solution, while causing less frequent and less severe hyperemia. ${ }^{215}$ Allergan patented this new formulation, and obtained FDA approval to market Lumigan $0.01 \%$ for the same indications as the original Lumigan $0.03 \%$ product. ${ }^{216}$ Significantly, without the prospect of effective patent protection for the new formulation, Allergan would have had little incentive to make the substantial investment in time and money to develop and obtain FDA approval for this improved formulation.

Generic companies challenged Allergan's formulation patents on a number of grounds, including the alleged obviousness of the invention, but ultimately the Federal Circuit affirmed a district court's decision upholding the validity of the

\footnotetext{
208. $I d$.

209. Id. at 1298-99.

210. Id. at 1298 .

211. Id.

212. $I d$.

213. Id.

214. Id. at 1298-99.

215. Id.

216. Id.
} 
patents. ${ }^{217}$ The district court found the solution to the problem at which Allergan scientists ultimately arrived was not only unexpected, it was in fact actively discouraged by the teachings of the prior art. ${ }^{218}$ For example, the prior art taught that the use of BAK as a preservative should be minimized in ophthalmic formulations to avoid safety problems, and the appellants' own expert, in summarizing the prior art's widespread concern regarding the chemical's toxicity, described BAK as "a natural-born killer" that was "from Satan." ${ }^{219}$ The district court found that, prior to Allergan's invention, "BAK was known to cause increased IOP, hyperemia, dry eye, and damage to corneal cells, and to exacerbate other eye disorders," and that "those known side effects would have discouraged a person of ordinary skill from using higher concentrations of BAK in a bimatoprost formulation, especially when fifty ppm BAK was known to be an adequate preservative in Lumigan $0.03 \%$."220

The district court also found the prior art taught that BAK would not increase the permeability of bimatoprost, but in fact, might actually decrease it. ${ }^{221} \mathrm{~W}$ orking against this conventional wisdom, "Allergan's inventors surprisingly determined that the opposite was true, namely, that $200 \mathrm{ppm}$ BAK enhanced the permeability of bimatoprost." 222 According to the Federal Circuit, the record showed "that the prior art 'criticize[d], discredit[ed], or otherwise discourage[d]' the use of 200 ppm BAK in a bimatoprost formulation. ${ }^{, 223}$ The Federal Circuit concluded that "the district court did not clearly err in finding that the claimed formulation exhibited 'unexpected results,' which differed in kind, not just in degree, from the prior art." 224 In effect, by investing in research that explored alternative formulation strategies that ran counter to conventional wisdom, Allergan scientists had come up with a fundamentally different product-one that could not have been predicted based on prior knowledge, and one which provided patients with a safer and more effective course of treatment.

This is the very sort of innovation that should be promoted by patents. As noted by the Federal Circuit, the difference between the $0.03 \%$ and $0.01 \%$ formulations is essentially "the difference between an effective and safe drug and one with significant side effects that caused many patients to discontinue treatment. ${ }^{225}$ Unfortunately, the recommendations of the Guidelines cast a shadow of uncertainty over the availability of effective patent protection for inventions of this type. ${ }^{226}$

It is important to remember that Allergan's patents on the $0.01 \%$ formulation

217. Id. at $1297-98$.

218. Id. at $1301-02$.

219. Id. at 1305.

220. Id.

221. Id. at 1306.

222. Id.

223. Id. (quoting In re Mouttet, 686 F.3d 1322, 1334 (Fed. Cir. 2012)).

224. Id.

225. Id. at 1307.

226. See Guidelines, supra note 1, at 36 . 
would not cover the original formulation and hence, should not create an obstacle to any generic company that decides to bring the original $0.03 \%$ formulation to the market. ${ }^{227}$ Of course, in view of its improved safety-efficacy profile, doctors and their patients might prefer the newer formulation. But if that is the case, it is only because the new formulation represents a significant medical advance, and thus a patent on the formulation is doing exactly what patents are intended to do, i.e., spur the development of improved modes of therapeutic treatment. Once the new formulation patents expire, generic companies will be free to sell versions of the new $0.01 \%$ formulation. ${ }^{228}$ Prior to their expiration, the market can decide whether the improvement of the new formulation justifies the cost differential between it and generically available $0.03 \%$ formulation.

Another example of the sort of re-formulation that can substantially improve therapeutic outcome involves the development of a modified-release dosage form of an already approved drug. In a typical scenario, a drug is initially introduced on the market as an immediate-release formulation that releases the drug into the bloodstream over a relatively short timeframe. One downside of this rapid release is that, because the drug is constantly being metabolized, the patient is required to take multiple doses each day, which often leads to problems in patient compliance. Furthermore, multiple doses and rapid metabolism can lead to peaks and valleys in blood levels of the drug, with an initial spike shortly after the drug is taken followed by low blood concentrations in the period of time preceding the next administration of the drug.

The process of generating and obtaining FDA approval for a modified-release formulation is, however, expensive and fraught with unpredictability. ${ }^{229} \mathrm{~W}$ ithout a patent incentive, drug companies would be less inclined to invest in the development of these products. Unfortunately, the Guidelines would disincentivize their development by casting doubt on the inventiveness of new formulations. ${ }^{230}$ To the contrary, the actual story of the development of a specific modified-release formulation drug that was the subject of a recent patent infringement lawsuit serves to illustrate how nonobvious the development of an effective modified-release form can be.

The drug is Amrix, a modified-release dosage form of the skeletal muscle relaxant cyclobenzaprine hydrochloride, which was the subject of a 2012 Federal Circuit decision entitled In re Cyclobenzaprine Hydrochloride Extended-Release Capsule Patent Litigation. ${ }^{231}$ Prior to the invention, patients were required to take the original rapid-release formulation of cyclobenzaprine hydrochloride multiple

227. Allergan, 796 F.3d at 1299.

228. See Allergan, Inc. v. Sandoz, Inc., No. 6:11-cv-441, 2014 WL 12622277, at*37 (E.D. Tex. Jan. 13, 2014), aff'd, 796 F.3d 1293 (Fed. Cir. 2015).

229. Mathew Herper, The Truly Staggering Cost of Inventing New Drugs, Forbes (Feb. 10, 2012, 7:41 AM), https://www.forbes.com/sites/matthewherper/2012/02/10/the-truly-staggeringcost-of-inventing-new-drugs/\#52cdd6b64a94 [https://perma.cc/W773-V79P].

230. See generally Guidelines, supra note 1.

231. 676 F.3d 1063, 1081-82 (Fed. Cir. 2012). 
times each day. ${ }^{232}$ On the other hand, the improved modified-release formulation embodied in Amrix can be taken once a day without sacrificing efficacy. ${ }^{233}$ Although some might assume it is straightforward and non-inventive to develop a once-a-day formulation of an existing drug, in fact the process can be unpredictable and entirely counter-intuitive.

The challenge of creating an effective extended-release version of a drug like cyclobenzaprine hydrochloride is highlighted by the fact that the immediaterelease formulation existed for decades prior to the development of Amrix, even though the need for the administration of multiple doses each day had resulted in "poor patient compliance." 234 The demand for an extended-release version was clearly present, but the formulation that eventually proved effective was far from obvious, as evidenced by multiple failed attempts by other pharmaceutical companies.

In the 1990 s, for example, a pharmaceutical company called ALZA attempted to develop an extended-release cyclobenzaprine formulation. ${ }^{235}$ After investing $\$ 10$ million, the company found itself unable to come up with an effective extended-release cyclobenzaprine formulation. ${ }^{236}$ Success in the form of Amrix came only after another company, Cephalon, decided to take a very different approach. ${ }^{237}$ Without the promise of patent protection, one would not expect a company to invest millions of dollars for the mere possibility of developing an effective product, particularly given the huge cost associated with bringing a drug product to market.

In the case of cyclobenzaprine, part of the difficulty had to do with the unpredictable relationship between the pharmacokinetic (PK) and pharmacodynamic (PD) properties of the drug. ${ }^{238}$ Pharmacokinetics is essentially the study of what a person's body does to a drug after administration, which is the net result of various processes such as absorption, distribution, localization in tissues, biotransformation, and excretion. ${ }^{239}$ As such, pharmacokinetics can be used to describe the amount of drug in a patient's blood plasma as a function of time following administration of the drug. Pharmacodynamics, on the other hand, describes the effect the drug renders on a person's body, i.e., the relationship between dose and response. ${ }^{240}$ To put it simply, to develop an extended-release formulation it is necessary to develop a formulation that provides a PK profile

232. Id. at 1081.

233. Id. at 1066 .

234. Id. at 1083 .

235. Id. at 1081.

236. Id.

237. Id. at 1082.

238. Id. at 1067.

239. Miller-Keane \& Marie T. O’Toole, Encyclopedia and Dictionary of Medicine, Nursing, AND Allied Health (Saunders, an imprint of Elsevier, Inc. 7th ed. 2003).

240. In re Cyclobenzaprine Hydrochloride Extended-Release Capsule Patent Litig., 676 F.3d at 1067 . 
that results in an effective $\mathrm{PD}{ }^{241}$ This can be challenging, and at times the solution to the problem can be counterintuitive.

For example, when ALZA sought to develop an extended-release formulation of cyclobenzaprine hydrochloride it began by calculating a PK profile for a patient who had been administered an immediate-release product multiple times over the course of the day. ${ }^{242}$ This profile is characterized by peaks and valleys, with the peaks occurring at the point where the drug enters the bloodstream. ALZA scientists made the reasonable decision to develop an extended-release formulation that provides patients with a constant dosage of an active ingredient in the blood serum that is less than the maximum, but higher than the minimum experienced with the immediate-release product. ${ }^{243}$ Their scientists predicted that this dosage would avoid the negative effects of the spikes, while maintaining a level that exceeds the low valleys, thereby providing the desired therapeutic effect. ${ }^{244}$ Unfortunately, although this approach made sense in principle, in practice the pharmacodynamics of this sustained-release formulation was not good, and the resulting product proved to be ineffective. ${ }^{245}$ A $\$ 10$ million investment ultimately resulted in no product. ${ }^{246}$

The inventors of Amrix took a very different approach. ${ }^{247}$ They created a formulation which produced a maximum blood plasma level of the active ingredient that exceeded the maximum experienced by patients taking the original immediate-release formulation, and a minimum blood level concentration that was even lower than experienced by patients who took the original formula. ${ }^{248} \mathrm{~A}$ different approach than ALZA, but this very different pharmacokinetic profile resulted in better pharmacodynamics, which translated into a viable drug that provides a therapeutically effective form of cyclobenzaprine hydrochloride that can be taken once a day. ${ }^{249}$ The Federal Circuit found that in view of these considerations and others, the district court had been correct in rejecting an obviousness challenge to Cephalon's patent directed toward the extended-release formulation embodied in Amrix. ${ }^{250}$

In re Omeprazole Patent Litigation provides another example of a case where the courts found that a useful drug formulation was not obvious. ${ }^{251}$ The active ingredient at issue in the case, omeprazole, is a potent inhibitor of gastric acid secretion and sold under the trade name Prilosec for use in the treatment of gastroesophageal reflux disease (GERD) and other conditions caused by excess

241. Id.

242. Id. at 1081.

243. Id.

244. Id.

245. Id.

246. Id.

247. Id. at 1081-82.

248. Id. at 1082 .

249. Id.

250. Id. 1081-82.

251. 536 F.3d 1361, 1380-81 (Fed. Cir. 2008). 
stomach acid. ${ }^{252}$ Omeprazole is susceptible to degradation in an acidic environment, which, given the highly acidic environment of the stomach, is a problem. ${ }^{253}$ An enteric coating can be applied to shield omeprazole from the acid in the stomach, allowing it to make its way intact to the small intestine, from which it is taken up by the body. ${ }^{254}$ Unfortunately, enteric coatings themselves contain acidic components, which can react with and degrade omeprazole during storage of the drug. ${ }^{255}$ To counteract this effect, alkaline reacting compounds ("ARCs") can be added to the drug core to increase omeprazole stability, increasing the storage stability of the omeprazole core, but this can in turn compromise the enteric coating and cause it to dissolve. ${ }^{256}$

In short, prior to the invention there was a need for an improved omeprazole formulation that protects the active ingredient from degradation during storage and while the drug makes its way through the stomach, but that quickly releases the active ingredient to the body once in the small intestine. The inventors addressed this need by devising a formulation of the drug that includes an inert sub-coating positioned between the enteric coating and the omeprazole core. ${ }^{257}$ This sub-coating increases storage stability and provides sufficient gastric acid resistance to prevent omeprazole from degrading in the stomach. ${ }^{258}$ The subcoating is designed to rapidly disintegrate in water, so once the dosage reaches the small intestine the water that is present there dissolves the sub-coating, resulting in rapid release of the active ingredient. ${ }^{259}$

Generic drug companies challenged the validity of two patents directed toward the improved omeprazole formulation, arguing it would have been obvious to those skilled in this area of technology to use the claimed sub-coating in combination with an enteric coating. ${ }^{260}$ However, the district court rejected this argument, and its finding of nonobviousness was affirmed on appeal by a unanimous panel of the Federal Circuit. ${ }^{261}$

The judges found the generic companies had failed to provide evidence that one of skill in the art would have recognized the need to include a sub-coating in the formulation. ${ }^{262}$ The prior art neither disclosed nor suggested a negative interaction between a drug core containing omeprazole and the enteric coating. ${ }^{263}$ Furthermore, the court found that one of skill in the art would have had no reason

252. Id. at 1365 .

253. Id.

254. Id.

255. $I d$.

256. $I d$.

257. $I d$.

258. $I d$.

259. Id.

260. Id. at 1380.

261. Id. at 1382 .

262. Id. at 1380.

263. Id. 
to infer that a negative interaction would occur. ${ }^{264}$ In short, the prior art failed to suggest that there was a problem - to the contrary, a number of experts testified that prior to the invention, those skilled in the field would have thought that the use of nothing more than an enteric coating would be the best approach to deal with the acid instability of omeprazole, and that "a person of skill in the art would not have believed that an enteric coating would create a problem resulting from contact with omeprazole." 265

Furthermore, the court found that even if one of skill in the art had recognized that there would be a negative interaction between the enteric coating and the drug core, there was nothing in the prior art suggesting the use of a sub-coating to address the problem. ${ }^{266}$ In fact, one of skill in the art would have envisioned multiple potential approaches to addressing the negative interaction other than the use of a sub-coating. For example, upon recognizing the problem, the skilled pharmaceutical chemist might have opted for abandoning the enteric coating altogether. The prior art was replete with examples of omeprazole products that did not employ an enteric coating. ${ }^{267}$ Alternatively, a skilled chemist might have opted for modifying the enteric coating itself, perhaps by removing monomers and small acidic pieces from the coating, or by using an inert coating, to name a few examples. Yet another alternative would have been to try altering the drug core by adding an antioxidant.

Even in a case where out of all these alternatives the skilled pharmaceutical chemist decided to try using a sub-coating, she would not necessarily have turned to a water-soluble sub-coating, particularly given the fact that omeprazole is sensitive to moisture and must successfully traverse the stomach without degradation prior to delivery to the alkaline environment of the small intestine. Given these considerations, the court found that one of skill in the art would have been more likely to try a non-soluble sub-coating, or, in the alternative, a subcoating containing a fatty acid. ${ }^{268}$

Likewise, in Canada a federal court also upheld the nonobviousness of patent claims directed toward the formulation of omeprazole used in Prilosec, for much the same reason as the Federal Circuit did in the case discussed above. ${ }^{269}$ The Canadian court concluded that omeprazole was a "particularly difficult API [active pharmaceutical ingredient] to formulate," that "[n]ot all of its idiosyncrasies were known in the prior art," and that "AstraZeneca did not know from the outset the difficulties it was facing or the means by which they could be overcome." 270 The court noted that the solution to the problem was "multifaceted," requiring AstraZeneca to "finely balance the incompatibility between alkalinity necessary for acceptable storage stability and the preservation

264. $I d$.

265. Id.

266. Id.

267. Id. at $1380-81$.

268. Id.

269. See generally AstraZeneca Canada Inc. v. Apotex Inc., [2015] F.C. 322 (Can.).

270. Id. at para. 244. 
of the enteric coating necessary for good gastric acid resistance." 271 The Canadian court concluded the work that went into the development of the patented formulation was "complex and time-consuming [and] decidedly not routine bench-work." $" 272$ The court recognized that the inventors struggled to overcome formulation problems and ultimately "explored a number of options before it found an omeprazole formulation viable for Phase III clinical studies and, ultimately, for commercial exploitation." 273

In a similar manner, the Federal Circuit in Cadence Pharmaceuticals v. Exela PharmSci unanimously rejected a generic company's challenge of a patent on an improved formulation that protected a drug active ingredient from degradation. ${ }^{274}$ The active ingredient at issue in the case was the widely used anti-inflammatory acetaminophen. ${ }^{275}$ In aqueous solutions, acetaminophen is prone to decomposing into potentially toxic products. ${ }^{276}$ The prior art taught the use of a free radicalcapturing agent to inhibit decomposition, but according to expert testimony this approach resulted in a formulation that was only stable for several months. ${ }^{277}$ The inventors of the patent at issue discovered that by deoxygenating a solution comprising acetaminophen, the drug's stability could be increased to two years. ${ }^{278}$ The patent disclosed and claimed a method for obtaining stable acetaminophen formulations by deoxygenating solutions with an inert gas to achieve oxygen concentrations below two parts-per-million ("ppm"). ${ }^{279}$ The patented process is used by the patent owner, Cadence Pharmaceuticals Inc., in the production of a stable, injectable acetaminophen product marketed under the name Ofirmev. ${ }^{280}$

In Cadence Pharmaceuticals, the generic challenger argued it would have been obvious to improve the stability of acetaminophen formulations through deoxygenation based on a prior art article that taught the use of deoxygenation to improve the stability of pyrogallol. ${ }^{281}$ Pyrogallol is not a drug, but rather a chemical compound known for being particularly sensitive to oxidation in the presence of oxygen. ${ }^{282}$ In fact, because it is so prone to oxidation, turning from white to brown in the presence of oxygen, pyrogallol is sometimes used to calculate the amount of oxygen in air. ${ }^{283}$

In contrast, the prior art taught that acetaminophen was sensitive to

271. Id.

272. Id. at para. 272 .

273. Id.

274. See generally 780 F.3d 1364 (Fed. Cir. 2015).

275. Acetaminophen is sometimes referred to as "paracetamol."

276. Cadence Pharm., 780 F.3d at 1367.

277. Id. at 1376.

278. $I d$.

279. Id. at 1367.

280. Id. at 1368 .

281. Id. at 1374.

282. Pyrogallol, WiKiPEDIA, https://en.wikipedia.org/wiki/Pyrogallol\#Uses [https://perma.cc/B64Y-54KT] (last visited Mar. 21, 2017).

283. $I d$. 
degradation, not due to oxidation, but rather through hydrolysis, i.e., by reaction with water, not oxygen. ${ }^{284}$ On appeal, the Federal Circuit found the district court had been correct in concluding that a reference article that teaches deoxygenation to protect pyrogallol from oxidation did not render it obvious to use deoxygenation to protect acetaminophen from hydrolysis. ${ }^{285}$ The district court also found deoxygenation of an acetaminophen solution to less than two ppm oxygen was technically difficult, further bolstering the non-obviousness of the invention. ${ }^{286}$ The district court pointed to other objective factors supporting a finding of non-obviousness, including the fact the invention fulfilled a long-felt need, was a commercial success, was licensed, and was the subject of praise in the industry. ${ }^{287}$

Similarly, in Novartis Pharmaceuticals v. Watson Laboratories, the Federal Circuit found that

[a]lthough the addition of an antioxidant would have been an obvious solution for a formulation with known oxidation problems, .... Without the knowledge of a problem, one of skill in the art would not have been motivated to modify GB ' 040 with antioxidants as purportedly disclosed in the ' 807 patent or the Elmalem article. ${ }^{288}$

Leo Pharmaceutical Products v. Rea is another recent example of a case in which a unanimous panel of the Federal Circuit rejected the argument that a patent on a new formulation of a drug was obvious, based in part on the fact that prior to the invention, those of skill in the art did not even recognize the existence of the problem, let alone provide a practical means for solving it. ${ }^{289}$ The drug at issue in this case was a combination product comprising a vitamin $\mathrm{D}$ analog and a corticosteroid, used in the treatment of psoriasis, which the Federal Circuit described as a "painful and socially debilitating disease. ${ }^{, 290}$ Prior to the drug's invention, it was known that the speed and efficacy of corticosteroid treatment could be improved by combining it with vitamin D treatment. ${ }^{291}$ However, at that time no one knew how to create a storage-stable combination of vitamin D and corticosteroid in a single formulation. ${ }^{292}$ Due to the unavailability of a storagestable combination product, physicians prescribed a two-drug regimen that required patients to apply one drug in the morning and another at night, the difficulty of which resulted in patient compliance issues. ${ }^{293}$

After recognizing the storage stability problem, scientists at Leo

284. Cadence Pharm., 780 F.3d at 1375.

285. Id.

286. Id. at 1374 .

287. Id.

288. 611 F. App’x 988, 996 (Fed. Cir. 2015).

289. 726 F.3d 1346, 1353-54 (Fed. Cir. 2013).

290. Id. at 1348 .

291. Id. at 1349 .

292. Id.

293. Id. 
Pharmaceuticals sought to develop a storage-stable formulation combining a vitamin D analog and a corticosteroid. ${ }^{294}$ After numerous unsuccessful attempts, they discovered that a new set of solvents, including polyoxypropylene 15 stearyl ether (POP-15-SE), solved the storage stability problem, thereby permitting the vitamin $\mathrm{D}$ analog and the corticosteroid to coexist in a single pharmaceutical product. ${ }^{295}$ Leo Pharmaceuticals obtained a patent on the formulation, U.S. Patent Number 6,753,013 (““013 patent”). ${ }^{296}$

A third-party requestor challenged the ' 013 patent in an inter partes reexamination. ${ }^{297}$ The Board of Patent Appeals and Interferences initially ruled that challenged claims in the patent were unpatentable based on obviousness, ${ }^{298}$ but a unanimous panel of the Federal Circuit reversed. ${ }^{299}$ The procedural posture and standard of review applied by the Federal Circuit in this case is significant. Even though the Federal Circuit is required to review the Board's findings of fact under the highly deferential "substantial evidence" standard, the appellate panel unanimously found the Board was incorrect to declare the claims invalid..$^{300}$

In particular, the Federal Circuit in Leo Pharmaceutical Products found the prior art relied upon by the Board "either [1] discouraged combining vitamin D analogs and corticosteroids in a single formulation, or [2] attempted the combination without recognizing or solving the storage stability problems associated with the combination." ${ }^{301}$ The court acknowledged that "an invention can often be the recognition of a problem itself." ${ }^{302}$ The court then pointed to prior art that recognized the instability problem, which results from the fact that while vitamin $\mathrm{D}$ is unstable at low $\mathrm{pH}$, corticosteroids are unstable at high $\mathrm{pH}^{303}$ As a consequence, prior to the invention, those skilled in the art generally believed that there was no $\mathrm{pH}$ range that would be suitable for the combination product. ${ }^{304}$ In view of this incompatibility of $\mathrm{pH}$ requirements, the prior art taught that although it was "only natural" that clinicians would attempt to combine the two ingredients, given the advantage of avoiding a two-drug regimen and resulting patient compliance issues, they should not do so because such a combination would be unstable. ${ }^{305}$

The Federal Circuit found that although there was some prior art that described attempts to combine a vitamin D analog with a corticosteroid, the authors of this prior art had failed to recognize or address the consequent stability

294. Id.

295. Id.

296. Id. at 1348 .

297. Id.

298. See Ex parte Leo Pharm. Prods., No. 2012-003165 (B.P.A.I. Apr. 30, 2012).

299. Leo Pharm. Prods., 726 F.3d at 1348.

300. Id.

301. Id. at 1353.

302. Id. (citing Cardiac Pacemakers v. St. Jude Med., 381 F.3d 1371, 1377 (Fed. Cir. 2004)).

303. Id.

304. Id.

305. Id. 
problems. ${ }^{306}$ In fact, when other researchers attempted to produce the combinations proposed by this prior art they were found to be unstable..$^{307}$ Furthermore, the court found that, because this prior art did not even recognize or suggest the existence of a stability problem, it would not have motivated other researchers to attempt to find an improved formulation with better stability. ${ }^{308}$

The court in Leo Pharmaceutical Products found particular significance in the fact that the prior art the Board concluded would have been obvious to combine to arrive at the claimed invention was available for more than a decade prior to the invention, undercutting any suggestion that it would have been obvious to make the combination. ${ }^{309}$ The court found "the intervening time between the prior art's teaching of the components and the eventual preparation of a successful composition speaks volumes to the nonobviousness of the ... patent." ${ }^{\text {"10 }}$

As a general matter, any assumption that creating an improved formulation is generally obvious fails to take into account the large number of variables that can be modified in a formulation, and the unpredictability as to the impact in terms of efficacy. As correctly observed by the Federal Circuit in Intendis GmbH v. Glenmark Pharmaceuticals, "swapping ingredients in complex chemical formulations is anything but "routine." "311

A good example of this is in Purdue Pharma L.P. v. Depomed, a case involving patents owned by Depomed, and directed generally toward a controlled-release oral dosage form of a soluble drug. ${ }^{312}$ The patented formulation comprised of a drug active ingredient dispersed within a solid matrix of polymers. ${ }^{313}$ After a patient takes the drug orally the polymeric matrix swells in the stomach, as the result of an uptake of water, and remains substantially intact while the drug is released in the stomach. ${ }^{314}$ This dosage form allows a soluble drug to be administered orally in a manner that prolongs its release, which is particularly useful in drugs such as opioids that are prone to abuse. ${ }^{315}$ Purdue Pharma used this technology, for example, in its reformulated OxyContin product (oxycodone hcl extended release tablets) designed to thwart abuse of this highly addictive painkiller. ${ }^{316}$

306. Id. at 1354 .

307. Id. at $1356-57$.

308. Id.

309. Id. at 1354 .

310. Id. at 1359 .

311. 822 F.3d 1355, 1366 (Fed. Cir. 2016).

312. See generally 643 F. App'x 960 (Fed. Cir. 2016).

313. Id. at 961 .

314. Id.

315. Id.

316. Depomed (DEPO) Announces Favorable Appeals Court Ruling in Purdue Pharma Case, STREETInsider.CoM (Mar. 24, 2016, 4:29 PM), http://www.streetinsider.com/Corporate+ News/Depomed $+($ DEPO $)+$ Announces + Favorable + Appeals + Court + Ruling + in + Purdue + Pharma +Case/11447941.html [https://perma.cc/2X9D-GVYJ]. 
Depomed's patents were challenged in an inter partes review proceeding that resulted in a trial before the Patent Trial and Appeal Board. The Board upheld the validity of the patents over the prior art, a decision that was affirmed on appeal by the Federal Circuit. ${ }^{317}$ The court's finding of non-obviousness was strongly supported by the testimony of experts in drug formulation, who described the large number of independent parameters that can be varied in designing and optimizing the formulation of a drug. ${ }^{318}$

For example, Doctor Hal Hopfenberg, Professor Emeritus of Chemical and Biomolecular Engineering at the North Carolina State University, submitted declarations in the inter partes review proceedings explaining the complexity of drug formulation development. ${ }^{319}$ Professor Hopfenberg has more than fourtynine years of academic and practical experience in chemical engineering and pharmaceutical industries, including involvement in the research and development of pharmaceutical formulations. ${ }^{320}$ His declarations expressed his view that one of skill in the art would have found it very challenging to arrive at the patented formulation "due to the plethora of structural complexities controlling polymer properties" and "[t]he extraordinarily complex set of structural variables leading to a large set of 'formulation considerations' affecting matrix properties. ${ }^{321} \mathrm{He}$ went on to explain the different formulation considerations that come into play in attempting to develop a beneficial controlled-release product, including

molecular weight, chemical substitution, particle size, hydration rate effects, polymer content, dosage form, dosage size, [and] manufacturing processes. In particular, he noted that "[b]ecause of the complexity of this multidimensional combination of structural, compositional and formulation variables, it would be uniquely challenging for a person of skill in the art to formulate a particular dosage form that remains 'substantially intact' following immersion in gastric fluid until substantially all of the drug is released.",322

Ms. Louie-Helm, a named inventor on the Depomed patents, also submitted a sworn declaration to the Board. ${ }^{323} \mathrm{Ms}$. Louie-Helm's declaration explained there were "numerous factors" to be considered in any particular formulation, "including 'solubility of the drug, molecular weight of the polymers, matrix chemical structure, particle size of both the drug and polymer, type of polymer, drug loading, dosage form size, and manufacturing processes." ${ }^{324}$ She went on

317. Id.

318. Purdue Pharma L.P., 643 F. App'x 960 at 966.

319. Brief for Appellee at 16, Purdue Pharma L.P., 643 F. App'x 960 (Nos. 2015-2029, -2030, -2032).

320. Id.

321. Id. at 17.

322. Id. at 17-18 (quoting Dr. Hopfenberg's trial testimony).

323. Id. at 18-19.

324. Id. at 19 (quoting Ms. Louie-Helm's sworn declaration). 
to explain how the inventions were the result of "several years of research, manipulation of different formulation variables in the laboratory, numerous dissolution experiments, and repeated testing to achieve a system that accomplished slow release of drug by diffusion over a particular length of time while keeping the polymeric matrix substantially intact." ${ }^{, 325}$ Between 1993 and 1996, Ms. Louie-Helm and her co-inventor studied the drug release-controlling properties of various polymers, and during that time period she contacted vendors to order different types of polymers and made pellets of different sizes to test swelling, dissolution profiles, and the physical integrity of different dosage forms. ${ }^{326}$ During those years of research, she "created an extensive library of polymers and their properties, such as swelling capacity and dissolution profiles when used in a dosage form." ${ }^{327}$ The polymer vendors that she contacted in the course of her research, such as Dow and Union Carbide, were not aware of use of polymers of high molecular weight that resulted in the type of release profiles sought by the inventors. ${ }^{328}$ As a consequence of this complexity, it took three years of testing certain polymers for the inventors to arrive at the patented formulation. ${ }^{329}$

Dr. Nicholson, Professor at Cornell University's Department of Policy Analysis and Management, submitted a declaration to the Board of the commercial success of Depomed's patented technology. ${ }^{330}$ Dr. Nicholson focused his opinion on healthcare economics, which included a comprehensive analysis of Depomed's Gralise product, which employs the patented technology and is used to treat patients with postherpetic neuralgia ("PHN"). ${ }^{331}$

While discussions of "evergreening" often seem to suggest that when a drug company obtains a new patent directed toward an invention relating to a previously patented pharmaceutical, this subsequent patent somehow extends the duration for which generic competition is precluded. But as a general matter, that is simply not the case. While new patents might preclude some newly invented uses, they generally do not stop a generic company from selling a competing version of the original drug for the originally approved indications.

An example of this can be seen with respect to the drug raloxifene. The Orange Book listing for this drug shows that Eli Lilly still has four non-expired patents directed toward the drug. ${ }^{332}$ At the same time, the Orange Book shows there are multiple generic companies that have been approved to market generic versions of the drug, albeit presumably not formulations of the drug covered by existing patents) or for any use that is currently covered by a patent.

European courts have also found patents directed toward new formulations

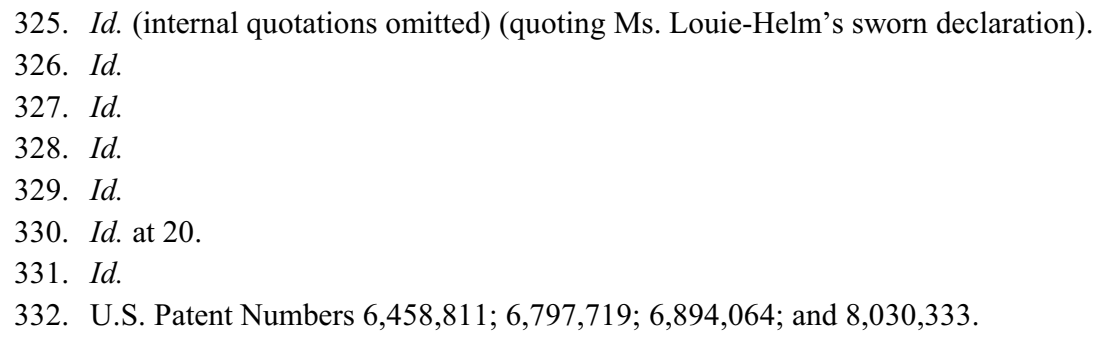


of existing drugs to be nonobvious. For example, in 2009, a Court of Appeals in the United Kingdom upheld the validity of a patent directed toward a sustainedrelease form of oxycodone. ${ }^{333}$ The U.K. court noted that prior to the patented invention oxycodone was widely viewed as a "minor weak opioid generally administered, to the extent that it was administered all, as a co-drug." ${ }^{, 334}$ The invention of the slow-release form transformed oxycodone into a serious alternative to morphine-something the court found to be entirely unexpected given the teaching of the prior art. ${ }^{335}$

Other European courts that have assessed the validity of related patents directed toward sustained-release oxycodone came to the same conclusion. ${ }^{336} \mathrm{~A}$ German court, for example, found the invention claimed in European patent EP 1810679 provided a method for substantially improving efficiency and quality of pain management in a manner that would not have been obvious to a person skilled in the art prior to the invention. ${ }^{337}$ In particular, the court found a skilled person would have had no reason to try using oxycodone hydrochloride as an alternative to known agents such as morphine and hydromorphone in a controlled-release dosage form. ${ }^{338}$

In Norway, the Borgarting Court of Appeal likewise upheld the validity of Norwegian patents relating to control-release oxycodone formulations (NO 307 028 and NO 318890$).{ }^{339}$ The court found the patented inventions credibly solved problems in the prior art relating to the use of morphine, which related to titration and dose variation. ${ }^{340}$ There were multiple opioids that could have been tried, and one of skill in the art would not have predicted that the oxycodone formulation would lead to lower dose variation and easier titration. For similar reasons, the Netherlands Rechtbank te 's-Gravenhage also upheld the validity of parallel Dutch patents. ${ }^{341}$

Rather than the blanket presumption against patents on new formulations endorsed by the Guidelines, which would tend to deny patent protection for both minor improvements and highly significant improvements, the needs of patients would be better served if the market and the judgment of patients and healthcare providers were allowed to determine the value of a new formulation on an existing drug. If the improvement is of such significance that it justifies a substantial cost premium, then society has benefited from the development of this improved mode of drug delivery, and payment of the premium is justified, in the same way that it is by development of a therapeutically useful new active

333. Eur. Pat. Off., Case Law from the Contracting States to the EPC 128 (3d ed. 2011).

334. Id.

335. Id.

336. Id. at 241-43.

337. Id. at 241 .

338. Id.

339. Id. at 245-46.

340. Id. at 246.

341. Id. at 242-43. 
ingredient. If the improvement is nominal, then payers should refuse to pay the premium, which they can do by simply purchasing the original formulation from generic companies at a discounted price. If there are market inefficiencies that somehow induce payers to pay the premium even though the improvement is minimal, then those market inefficiencies should be addressed, rather than attempting to address it by changing the standard for patentability in a discriminatory manner that targets specific categories of inventions.

\section{DosES}

The Guidelines recommend that product claims directed toward "the dose of a drug fail to comply with the industrial applicability requirement." ${ }^{342}$ This is similar to the Working Paper's recommendation that "[n]ew doses of known products for the same or a different indication" because such products "do not constitute inventions." ${ }^{343}$ To the contrary, however, new dosages can have dramatic effects on the safety and efficacy of drugs, and investment in researching and developing new and improved dosages of existing drugs should not be discouraged by a blanket prohibition on patent protection for any resulting product.

A good example is provided in the case of Lumigan, discussed above. ${ }^{344}$ Recall that Allergan scientists were able to substantially reduce serious negative side effects caused by their original formulation of Lumigan by reducing the dosage from $0.3 \%$ to $0.1 \%$, in conjunction with an increased concentration of BAK to improve corneal permeability. ${ }^{345}$ As noted by the court in that case, the change in formulation resulted in a change in kind, not just in degree, of the product, providing a superior health outcome for patients, which in some cases could mean the difference between retained sight and blindness. ${ }^{346}$

The Guidelines also argue that dose claims "in reality" cover a method of medical treatment, thus lacking industrial applicability. ${ }^{347}$ If taken seriously, this argument would seem to bar the patenting of pharmaceutical active ingredients in general. After all, a claim to a drug dose is no more equivalent to a method of using the drug than a claim to a novel active ingredient is equivalent to a claim to a method of using the active ingredient.

\section{COMBINATIONS}

The Working Paper recommended that patent claims directed toward combinations of previously known active ingredients should be deemed noninventive, apparently under any circumstances, i.e., even in a case where the combination results in a new and nonobvious synergistic effect that has been

342. Guidelines, supra note 1 , at 37.

343. Working Paper, supra note 2, at 8.

344. See supra Part VII.

345. Id.

346. Allergan, Inc. v. Sandoz Inc., 796 F.3d 1293, 1306 (Fed. Cir. 2015).

347. Guidelines, supra note 1, at 36. 
"properly demonstrated by biological tests and appropriately disclosed in the patent specifications." ${ }^{348}$ The Working Paper provided a number of purported rationales for this recommendation, which can be summarized as: (1) if "claims on combinations are accepted subsequent to a patent on the relevant active ingredient/s, the patent owner may be able to indirectly extend the term of protection granted under the basic patent," (2) "the synergy between two or more drugs may be deemed a 'discovery' rather than an 'invention,' since the synergy takes place in the body and is found through clinical trials," and (3) "in some cases, combination claims may in practical terms be equivalent to claims over medical treatments (the patentability of which is excluded in most countries), to the extent that they only provide a method of administering a combination of existing drugs." 349 None of these rationales withstand serious scrutiny. In fact, there are compelling reasons why at least some claims directed toward combination inventions should not be characterized as obvious per se.

Regarding the first rationale cited in the Working Paper, a patent that claims a pharmaceutical combination comprising active ingredient $A$ and active ingredient B would under no circumstances extend, either directly or indirectly, the term of protection of a "basic patent" directed toward either A or B. ${ }^{350}$ It is a well-established axiom of patent law that a product or process that would infringe a patent claim after the patent issues renders the claim invalid for lack of novelty if it is disclosed in the relevant prior art. ${ }^{351}$ If active ingredients A and B were already well known prior to the invention of the combination, patent claims directed toward the combination could not be infringed by any use, making, sale, or importation of these products. That would include use of the two products in combination, except in the context of the combination drug product. Thus, for example, the claim would not prevent anyone from using the knowledge that the combination of the drugs is particularly beneficial to take the two drugs concurrently but separately.

The Working Paper suggested that any synergy between two active ingredients should be discounted as an unpatentable "discovery" because such synergy "takes place in the body and is found through clinical trials." ${ }^{352}$ The same can be said for any pharmaceutically active ingredient, whether administered alone or in combination - the therapeutic effect occurs in the body and is observed and verified through clinical trials. However, pharmaceutical active ingredients are unquestionably patentable subject matter. Even the Working Paper never goes so far as to suggest that newly discovered pharmaceutical active ingredients should be declared patent ineligible simply because their effect occurs

348. Working Paper, supra note 2, at 8 .

349. Id.

350. See generally Working Paper, supra note 2.

351. See, e.g., Upsher-Smith Labs., Inc. v. Pamlab, LLC, 412 F.3d 1319, 1322 (Fed. Cir. 2005) ("A century-old axiom of patent law holds that a product "which would literally infringe if later in time anticipates if earlier.'”) (quoting Schering Corp. v. Geneva Pharms., Inc., 339 F.3d 1373, 1379 (Fed. Cir. 2003)).

352. Working Paper, supra note 2, at 8. 
in the body, or because they are the subject of clinical trials. Therefore, this is no justification for denying patent protection.

Finally, the Working Paper suggested that, "in practical terms," a claim to a combination drug is equivalent to a claim over medical treatment, since the combination product only provides a method of administering a combination of existing drugs. ${ }^{353}$ Once again, this argument must fail because, if taken seriously, it would bar the patenting of pharmaceutical active ingredients in general. A claim to a combination drug is no more equivalent to a method of using the drug than a claim to a novel active ingredient is equivalent to a claim to a method of using the active ingredient. Significantly, a claim directed to a combination product does not preclude anyone from taking the combination of drugs, so long as they are not administered in a single combination product. There can be advantages to combining the active ingredients in a single product, but a patent on the combination product would not prevent a patient from taking the two drugs concurrently and simultaneously.

Significantly, while the recommendations of the Guidelines largely track those of the Working Paper, the Guidelines explicitly depart from the Working Paper by acknowledging that a combination product can satisfy the inventive step standard when a synergistic effect can be demonstrated. ${ }^{354}$ Thankfully, the Working Paper's assertion that any synergy between two active ingredients should be discounted as an unpatentable "discovery" because such synergy "takes place in the body and is found through clinical trials" was excised from the Guidelines. ${ }^{355}$

In fact, there are good policy rationales supporting the availability of patent protection for inventive combination products, particularly, but not exclusively, when the combination results in a synergistic effect. Patents provide an incentive for innovators to discover combination products that provide improved therapeutic outcome compared to either individual active ingredient, and perhaps even more significantly, to fund the expensive human clinical trials necessary to verify and validate the clinical benefits of the combination. At the same time, a claim limited to the combination product in no way precludes patients and doctors from availing themselves of the combination, so long as they administer the drugs separately rather than in a single dosage.

The benefits of combination products are well known and have been documented. For example, studies have shown that patient adherence and compliance can be significantly improved by use of a combination product compared with multiple medications taken individually. ${ }^{356}$ These products have been widely adopted for diseases such as diabetes and cardiovascular disease, providing significant advantages over monotherapies, and resulting in improved

353. Id.

354. Guidelines, supra note 1, at 39.

355. Working Paper, supra note 2, at 8.

356. See generally Ajay K. Gupta et al., Compliance, Safety, and Effectiveness of Fixed-dose Combinations of Antihypertensive Agents: A Meta-analysis, 55 HYPERTENSION 399 (2010). 
patient compliance. ${ }^{357}$

Combination products improve patient compliance in part by reducing a patient's pill burden. ${ }^{358}$ Note that pill burden is not only the number of pills that need to be taken, but also the associated burdens such as keeping track of several medications, and understanding their various instructions. ${ }^{359}$

Another advantage arises from the ability to compose combined profiles of, for example, pharmacokinetics, effects, and adverse effects that may be specific for the relative dosages in a given combination product, providing a simpler overview compared with looking at the profiles of each single drug individually. Such a combined profile can also include effects caused by interaction between the individual drugs that may be omitted in individual drug profiles. Because combination products are reviewed by regulating agencies (such as the FDA in the United States), the active ingredients used in an approved combination product are unlikely to exhibit adverse drug interactions with each other.

Treximet provides a good example of a combination therapeutic that provides surprising and life-enhancing benefits, and with respect to which a district court and the Federal Circuit rejected an allegation of obviousness. ${ }^{360}$ Treximet is a combination of sumatriptan and naproxen sodium that is effective in the treatment of migraine headaches. ${ }^{361}$ The individual use of both active ingredient components was well-established prior to invention of the combination product. ${ }^{362}$ Sumatriptan (also known as Imitrex) was a standard treatment for migraine patients, and naproxen was a well-known nonsteroidal anti-inflammatory drug ("NSAID"). ${ }^{363}$

Prior to the invention of the combination, a significant number of users of sumatriptan suffered from "rebound headaches," where the headache initially went away but returned after a few hours, oftentimes even worse than before. ${ }^{364}$ The problem was known, but the solution was far from clear. ${ }^{365}$ Some doctors advised patients to address the problem by simply taking more sumatriptan, while pharmaceutical companies tried modifying the sumatriptan molecule itself. ${ }^{366}$ But Doctor Plachetka, the inventor of Treximet, took a different approach ${ }^{367} \mathrm{He}$ surmised that the rebound headaches were triggered by residual inflammation

357. See generally David S. Bell, Combine and Conquer: Advantages and Disadvantages of Fixed-dose Combination Therapy, 15 Diabetes OBesity \& Metabolism 291 (2013).

358. See generally Roger Collier, Reducing the "Pill Burden," 184 CANADIAN MED. Ass'N J. E117 (2012).

359. See id.

360. Corrected Brief for Appellee at 3-4, Pozen Inc. v. Par Pharm., Inc., 696 F.3d 1151 (Fed. Cir. 2012) (Nos. 2011-1584, -1585, -1586).

361. Id. at 49 .

362. Id. at 2 .

363. Id at 5 .

364. Id. at 3-4.

365. Id. at 4

366. Id.

367. Id. at 5 . 
which persisted even after treatment with sumatriptan, and he conceived the idea of addressing it through the simultaneous administration of sumatriptan and the anti-inflammatory naproxen. ${ }^{368}$ The result was Treximet, an improved product that provides longer-lasting relief for migraine patients while reducing the incidence of rebound. ${ }^{369}$

In order to secure FDA approval for Treximet, Plachetka and the pharmaceutical company he worked for (Pozen) sponsored and conducted extensive clinical studies to demonstrate and validate the safety, improved efficacy, and reduced relapse of the product. ${ }^{370}$ Activities such as these typically require the incentive of intellectual property protection in the form of a patent.

Various generic drug companies sought to bring a generic version of Treximet to the market, and were sued by Pozen for infringement of several patents, including a patent claiming effective combinations of sumatriptan and naproxen, i.e., the sort of combination patent that the Working Paper would have found per se unpatentable. ${ }^{371}$ The generic companies argued that the combination therapy was obvious, but the district court rejected these arguments, and a unanimous panel of the Federal Circuit affirmed this determination. ${ }^{372}$ The courts found that while there was prior art indicating that treatment with sumatriptan alone was not always effective for migraine patients, there was nothing to suggest combination with an NSAID like naproxen. ${ }^{373}$ If anything, the prior art would have suggested sequential (as opposed to concurrent) administration of sumatriptan with another agent like an NSAID. ${ }^{374}$

In Knoll Pharmaceutical Co. v. Teva Pharmaceuticals USA, Inc., the Federal Circuit reversed a district court decision that found obvious a patent directed tow ard a combination product comprising hydrocodone (an opioid) and ibuprofen (an NSAID) ${ }^{375}$ The patent, U.S. Patent Number 4,587,252, is exclusively licensed by Knoll Pharmaceutical Co., and the combination product is marketed under the trade name VICOPROFEN. ${ }^{376}$ The ' 252 patent is directed toward methods and compositions for treating pain by administering a combination of hydrocodone and ibuprofen in specified amounts, wherein the combination of the two active ingredients provides an additive effect, i.e., the analgesic effect of the combination product is greater than would be provided by the administration of either active group alone. ${ }^{377}$

The district court found the claims obvious in view of prior art that suggested

368. Id.

369. Id.

370. Id.

371. See, e.g., U.S. Patent No. 6,586,458, claim 3 (filed Apr. 27, 2000).

372. Pozen Inc. v. Par Pharm., Inc., 696 F.3d 1151, 1160-65 (Fed. Cir. 2012).

373. Id.

374. $I d$.

375. 367 F.3d 1381, 1382-83 (Fed. Cir. 2004).

376. Id. at 1383 .

377. Id. at $1384-85$. 
the desirability of developing an opioid-NSAID combination, ${ }^{378}$ but the Federal Circuit reversed after finding the evidence showed that other pharmaceutical companies had invested huge amounts of time and money in attempts to develop an opioid-NSAID combination drug with additive analgesic effect, but they had repeatedly failed in these attempts. ${ }^{379}$ Part of the difficulty stems from the fact there are numerous opioids and numerous NSAIDs, and consequentially a large number of potential combinations. But when drug companies began attempting to develop these combinations, they repeatedly found that they were unable to demonstrate an additive analgesic effect. ${ }^{380}$ At that time, FDA was requiring that an opioid-NSAID combination demonstrate this additive effect as a prerequisite to approval. ${ }^{381}$ Companies spent years conducting animal and human trials, only to have to give up after failing to establish an additive analgesic effect. ${ }^{382}$ If it had been obvious which combination supplied this additive effect, then logically one can assume that one of these companies would have developed the combination product much earlier than actually occurred.

Instead, it was not until the inventors of the ' 252 patent tried a specific combination of hydrocodone and ibuprofen that a combination product with the desired additive effect was finally developed. ${ }^{383}$ Not only was the effect additive, but studies showed that it was synergistic, providing even more relief than one would predict by adding the effects of the two individual components. ${ }^{384}$ This could not have been predicted based on the repeated failures of other drug companies when they tried other combinations and were unable to even show an additive effect. The product covered by the patent, Vicoprofen, is still the only opioid-NSAID combination to ever satisfy the FDA's requirement of an additive analgesic effect, and it is the only opioid-NSAID combination product ever to be marketed in the United States. ${ }^{385}$

During the 1980s, multiple drug companies, including the companies that marketed popular NSAID drugs such as naproxen and ibuprofen, invested heavily in years of testing various ratios and doses of different opioids combined with different NSAIDs, attempting to discover some combination that would have the desired additive effect. ${ }^{386}$ But none of these projects succeeded, and ultimately they were terminated without ever bringing a commercial product to market. ${ }^{387}$ In particular, these companies tried various combinations of different opioids, including codeine, morphine sulfate, methadone, oxycodone, and nalbuphine,

378. Id. at 1384 .

379. Id. at 1385 .

380. Brief of Plaintiffs-Appellants at 7-8, Knoll Pharm. Co., Inc., 367 F.3d 1381 (No. 031300).

381. Id. at 6 .

382. Id. at 9-10.

383. Id. at 6-7.

384. Id. at 13-15.

385. Id. at 7 .

386. Id. at 11-12.

387. Id. at 12-13. 
with a variety of NSAIDS including naproxen, ibuprofen, flurbiprofen, suprofen, zomepirac, tolmetin, proquazone, tiflamizole, sulindac, and indomethacin. ${ }^{388}$

These failed attempts occurred in spite of the fact there were powerful economic incentives motivating several of these companies to develop a successful product, particularly companies that already had brand-name recognition for their own NSAID products, e.g., Motrin and Anaprox. In spite of a combined investment of more than twenty years of animal studies and clinical research, none of these companies ever succeeded in developing a commercial product that provided the additive effect necessary for FDA approval. ${ }^{389}$

Sanofi-Aventis Deutschland GmbH v. Glenmark Pharmaceuticals Inc., provides another example of a case where the Federal Circuit upheld a district court's determination that a patent on a drug combination showing surprising synergistic effect was not obvious. ${ }^{390}$ The patent at issue, U.S. Patent Number $5,721,244$, covers a combination product that includes the angiotensin converting enzyme (ACE) inhibitor trandolapril and the calcium channel blocker (also called "calcium antagonist") verapamil hydrochloride in a single dosage, marketed for use as an antihypertension drug under the brand name Tarka. ${ }^{391}$ In this case, the Federal Circuit noted that while the generic drug challenger argued it would have been obvious to combine a calcium channel blocker with an ACE inhibitor, in fact there were hundreds, if not thousands, of potential combinations, and nothing to suggest that this particular combination would have particularly desirable pharmacological properties, including longer-lasting hypertension control, particularly given the widespread belief in the prior art that a double-ring inhibitor such as trandolapril would not be able to fit into the pocket structure of the ACE protein, and thus would not work as well as any of the many single-ring ACE inhibitors that were then available. ${ }^{392}$

At the time the patent application was filed, only two ACE inhibitors, enalapril and captopril, had been approved for the treatment of hypertension, and both had the significant problem of having a short duration of efficacy. ${ }^{393}$ As described by the patent owner:

Captopril needed to be dosed at least three times per day and enalapril needed to be dosed at least twice per day. Patients' blood pressure cycled up as each dose wore off and then back down in response to the next dose. This up-and-down cycling was disadvantageous because steady blood pressure control is important to the treatment of hypertension. Compliance with multiple-dose per day schedules was also a problem. In addition, the single-ring $\mathrm{ACE}$ inhibitor captopril was toxic to the

388. Id.

389. Id. at 7 .

390. 748 F.3d 1354, 1356 (Fed. Cir. 2014).

391. Id.

392. Id. at $1358-61$.

393. Id. at 1359 . 
kidneys. ${ }^{394}$

At the time of the invention, there were thousands of ACE inhibitors being developed and under consideration for use as drugs, but it was thought that these drugs acted by binding to the ACE pocket, and that two-ring structures such as trandolapril and quinapril were unlikely to be as effective as a single-ring ACE inhibitor, of which many were available for testing. ${ }^{395}$ In fact, scientists at the drug company Merck - the developers of enalapril and one of the leaders in ACE inhibitor development at the time-were modifying other features of the singlering structure to search for better ACE inhibitors, rather than attempting to move forward with a double-ring structure compound. ${ }^{396}$

Allergan, Inc. v. Sandoz Inc. provides another example in which the Federal Circuit rejected an obviousness challenge to a claim directed toward a formulation comprising a combination of two active ingredients, where the combination provided an unexpected and beneficial therapeutic outcome. ${ }^{397}$ In particular, the inventors discovered that by combining briminodine and timolol in a single composition, at specified concentrations, a combination product results which allows for a reduction in the number of daily applications of the drug from three times a day to two times a day, without any loss of efficacy. ${ }^{398}$

The EPO also recognizes unpredictability associated with achieving a synergistic effect in a combination product. In T1814/11, for example, an appeals board found a combination of the fungicidal agents prothioconazole and picoxystrobin inventive in view of the resulting synergistic effect, characterizing the synergy in this case as unforeseeable in principle. ${ }^{399}$

\section{PRODRUGS}

The Guidelines define a prodrug as "a precursor of a drug, which undergoes a chemical conversion by metabolic processes in the body before becoming therapeutically active," and notes that many medicines are commercialized as prodrugs. ${ }^{400}$ The Guidelines acknowledge that "[a] prodrug may have advantages compared to the basic drug (e.g. better stability and bioavailability, fewer side effects, better pharmacokinetic profile, increased concentration of the drug at the site of action, and longer duration of action)." ${ }^{401}$ The Guidelines do not recommend against the patentability of prodrugs in general, but do recommend

394. Response Brief of Plaintiffs-Appellees at 12, Sanofi-Aventis Deutschland GmbH, 748 F.3d 1354 (No. 2012-1489) (internal citations omitted).

395. Id. at 13 .

396. Id.

397. See generally 726 F.3d 1286 (Fed. Cir. 2013).

398. U.S. Patent No. 7,030,149, claim 4 (filed Apr. 19, 2002).

399. Supplementary publication 5, 5 Official Journal EPO 25, European Patent Office, https:/www.epo.org/law-practice/legal-texts/official-journal/2014/etc/se5/p25.html (May 2014) (T1814/11 throughout).

400. Guidelines, supra note 1 , at 39.

401. Id. at 42 . 
that "[a] claim on a prodrug will generally fail to meet the inventive step standard unless evidence is provided that overcomes pharmaceutical or pharmacokinetically based problems of the parent drug in a non-evident manner." 402

Inventive new prodrugs can provide substantial benefits and clearly should be incentivized by effective patent protection. An example can be seen in the case of Shire v. Amneal Pharmaceuticals, where the Federal Circuit upheld the validity of patent claims directed toward a prodrug of amphetamine engineered to decrease its potential for causing overdose or abuse. ${ }^{403}$ The Federal Circuit affirmed the district court's finding that the defendant generic companies had failed to identify prior art that would render obvious claims directed toward mesylate salts of the prodrug. ${ }^{404}$ The court also affirmed the nonobviousness of method claims directed toward use of the prodrug. ${ }^{405}$

The prodrug at issue in Shire is L-lysine-d-amphetamine ("LDX") dimesylate, which is basically amphetamine covalently linked to the amino acid L-lysine, sold by the patent owner Shire under the brand name Vyvanse. ${ }^{406}$ The closest prior art was an Australian patent, which apparently disclosed the idea of covalently linking amphetamine to some other molecule selected from a laundry list of molecules. The list included seventeen amino acids, each of which could be in the $\mathrm{L}$ or $\mathrm{D}$ chiral form, more than 100 other combinations of amino acids "and the like" having various protecting groups, and a list of other compounds which the court characterized as indefinite with respect to the number and identity of their constituents. ${ }^{407}$ Given the huge number of potential conjugates provided in these laundry lists, and the lack of any suggestion that L-lys in particular would be worth trying, the prior art did not provide any meaningful guidance pointing toward the particular prodrug actually found to be effective. ${ }^{408}$

\section{Metabolites}

The Guidelines define an active metabolite as "the compound that remains after a drug is metabolized by the body." 409 The Guidelines recommend that "[c]laims on metabolites are not admissible. They can be rejected on the grounds of absence of an invention or lack of novelty/inventive step." ${ }^{410}$ The Guidelines acknowledge that "there may be advantages in administering an active metabolite compared to the parent drug," but assert that "any advantages do not stem from

\footnotetext{
402. Id. at 12 .

403. 802 F.3d 1301, 1304 (Fed. Cir. 2015).

404. Id. at 1311 .

405. Id. at 1306-09.

406. Id. at 1304 .

407. Id. at 1307 .

408. Id. at 1306-09.

409. Guidelines, supra note 1 , at 41.

410. Id.
} 
inventive activity." ${ }^{411}$ The Guidelines also argue that metabolites are not novel, "based on the concept of inherency," and they "cannot be deemed an invention because they are naturally produced through the metabolism." 412

The Guidelines correctly point out that in Schering Corp. v. Geneva Pharmaceuticals Inc. the Federal Circuit held a claim directed to an antihistamine metabolite was inherently anticipated by a prior art patent disclosing the underlying antihistamine. ${ }^{413}$ However, the Guidelines fail to note that in Schering, the court emphasized that its decision "[did] not preclude patent protection for metabolites of known drugs," and that "[w]ith proper claiming, patent protection is available for metabolites of known drugs. ${ }^{, 414}$ The claims that were invalidated by the Schering court were "bare compound claims," which encompassed the compounds as chemical species in any surroundings, including within the human body as metabolites of a drug, and were thus anticipated by a prior art disclosure of a drug that metabolized into the claimed compound. ${ }^{415}$

The court explained that while "bare compound claims" of this sort are disallowed,

[a] skilled patent drafter, however, might fashion a claim to cover the metabolite in a way that avoids anticipation. For example, the metabolite may be claimed in its pure and isolated form ..., or as a pharmaceutical composition (e.g., with a pharmaceutically acceptable carrier). The patent drafter could also claim a method of administering the metabolite or the corresponding pharmaceutical composition. ${ }^{416}$

In fact, the patent at issue in Schering included a number of claims that were not found to be anticipated by the prior art, including claims reciting pharmaceutical compositions comprising the metabolite, and methods of treating allergic reactions by administering compounds that include metabolite. ${ }^{417}$ Of course, in order to be patentable claims of this sort it would need to satisfy the other requirements of patentability, such as nonobviousness. The Guidelines provide no basis for their conclusory assertion that any advantages associated with the pharmaceutical use of an active metabolite "do not stem from inventive activity." ${ }^{, 418}$ As for the suggestion that active metabolites are not patentable subject matter because they are produced through metabolic processes, the Guidelines appear to be confusing the patent eligibility of a naturally-occurring metabolite with the patent eligibility of a chemical compound resulting from the metabolism of a drug. A drug metabolite is no more a natural product than the drug from which it is derived, and so as a general matter drug metabolites should

\footnotetext{
411. $I d$.

412. $I d$.

413. 339 F.3d 1373, 1381 (Fed. Cir. 2003).

414. Id.

415. $I d$.

416. $I d$.

417. Id.

418. Guidelines, supra note 1 , at 41.
} 
easily pass muster as patentable subject matter.

\section{New Medical UsE}

The Guidelines recommend:

Claims relating to the new use of a known drug can be rejected on various grounds:

(a) it is the discovery of a property.

(b) there is no invention, given the absence of a technical character.

(c) there is no novelty, as the compound and its process of manufacture are known.

(d) absence of industrial applicability, since the effects take place in the body.

(e) exclusion of methods of medical treatment, when such exclusion is provided for in a national patent law. ${ }^{419}$

The Guidelines specifically point to AZT (zidovudine) as an example of a "new medical use," based on the fact that the drug that was initially studied as a potential cancer drug, but after further research and development was shown to be useful in the treatment of HIV. ${ }^{420}$ While the Guidelines extol the virtues of AZT as a "drug effective in both the treatment of AIDS and the reduction of mother-to-child transmission," and as the "first breakthrough in AIDS therapy," they fail to recognize the role that the availability of patent protection for new medical uses played in transforming AZT from a failed cancer drug to a breakthrough in AIDS treatment.

AZT would, in all likelihood, never have been developed as an AIDS drug were it not for a team of researchers at Burroughs-Wellcome (a pharmaceutical company) setting up a program to discover drugs with a potential to inhibit HIV replication. ${ }^{422}$ These pharmaceutical company researchers discovered that AZT is a potent inhibitor of retroviruses, and a search of the company's records showed that the compound had shown low toxicity when tested for its antibacterial activity in rats many years earlier. Based in part on these results, AZT was selected by Burroughs-Wellcome researchers as one of eleven compounds to send to the National Cancer Institute (NCI) for testing in that organization's HIV antiviral assay. ${ }^{423}$

The NCI conducted in vitro and Phase I clinical trials, the results of which indicated that AZT could be safely administered to patients, and that it showed "strong evidence of clinical effectiveness." ${ }^{24}$ However, as is typically the case,

419. Id. at 44 .

420. Id. at 42 .

421. Id.

422. Zidovudine, WiKIPEDIA, https://en.wikipedia.org/wiki/Zidovudine\#History [https://perma.cc/44BH-LZVL] (last visited Mar. 21, 2017).

423. Id.

424. Id. 
it was left to a pharmaceutical company, in this case Burroughs-Wellcome, to conduct a "rigorous double-blind, placebo-controlled randomized trial of AZT." ${ }^{25}$ The huge cost of these clinical trials dictates that they are usually only conducted by pharmaceutical companies, and only in cases where the pharmaceutical company perceives a likely return on investment, which in this case would only be possible through the protection provided by a patent covering this new medical use.

Both the NIH and CDC commended Burroughs-Wellcome for the high standards employed in these clinical trials, which for the first time prove that AZT safely prolongs the lives of patients with HIV. ${ }^{426}$ The time between the first demonstration that AZT was effective against HIV in the laboratory and its approval was twenty-five months, the shortest period of drug development in recent history. ${ }^{427}$ However, without the availability of patent protection for this new medical use of an old compound, it is very unlikely that AZT would have ever become an AIDS drug. Unfortunately, the Guidelines utterly fail to acknowledge the role of patents in providing the incentive necessary to turn a failed compound into a life-saving medicine.

The history of raloxifene hydrochloride (marketed as Evista by Eli Lilly and Company) provides another example of the importance of patent protection for new medical uses of known drugs. Raloxifene is an antiestrogen, a class of compounds that were initially developed for the treatment of estrogen-dependent breast cancer. ${ }^{428}$ Antiestrogens were found, however, to be associated with an increased risk of endometrial cancer, i.e., cancer of the uterus. ${ }^{429}$ Lilly researchers initially synthesized and tested raloxifene in an attempt to identify an antiestrogen that would have a therapeutic effect on breast cancer without the associated side effect affecting the uterus. ${ }^{430}$ Unfortunately, animal studies and Phase I human clinical trials of the drug candidate conducted in the 1970s and 1980s showed that the compound suffered from low bioavailability - in other words, very little of the raloxifene ingested by a patient made its way to the patient's bloodstream. ${ }^{431} \mathrm{~A}$ Phase II human clinical trial conducted by Lilly failed to show any antitumor activity in patients suffering from metastatic breast cancer, and the director of the trial recommended that the drug candidate should not be evaluated further for use against breast cancer, presumably due to the compound's poor bioavailability. ${ }^{432}$

In spite of these negative results and the poor prognosis for the compound ever becoming a useful drug, Lilly researchers persevered and ultimately found, in spite of the low bioavailability, the drug could be used to inhibit bone loss in post-menopausal women, i.e., to prevent osteoporosis. Osteoporosis is largely

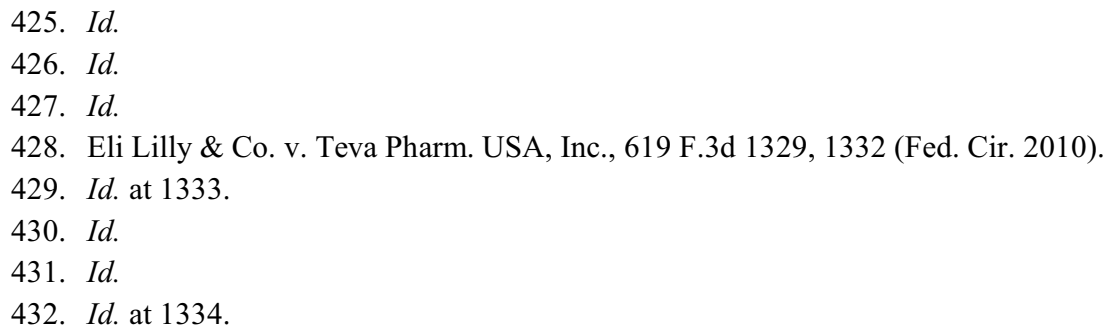


caused by the reduction in estrogen levels that occurs in women after menopause, and often results in osteoporotic bone fractures in women over fifty years of age. ${ }^{433}$ Historically, estrogen replacement therapy ("ERT") was a principal treatment for postmenopausal osteoporosis. ${ }^{434}$ Unfortunately, ERT has been associated with increased risk of both breast and uterine cancers, prompting a need for an improved alternative to estrogen. ${ }^{435}$

Lilly conducted the necessary research and development, including expensive human clinical trials, to secure FDA approval in 1997 to market raloxifene for use in the prevention of osteoporosis in postmenopausal women. ${ }^{436}$ But thanks to the promise of further patents to incentivize research into further uses, Lilly scientists did not stop there. ${ }^{437}$ They continued to search for additional beneficial uses of the drug, resulting in FDA approval in 1999 for use of raloxifene in the treatment (as opposed to prevention) of osteoporosis in postmenopausal women. ${ }^{438}$ In 2007 , FDA approved an additional use of the drug, this time for reducing the risk of invasive breast cancer in postmenopausal women with osteoporosis and in postmenopausal women at high risk for invasive breast cancer. ${ }^{439}$

Significantly, by the time Lilly received its initial FDA approval to market raloxifene for the prevention of osteoporosis in 1997, the original patent on raloxifene was due to expire within three years. ${ }^{440}$ Without the incentive of additional patent protection, in this case provided by a method of use patent specifically targeted to use of the compound for osteoporosis, Lilly would have been unlikely to pursue further research once it came to a dead end in its initial breast cancer studies. ${ }^{441}$

Generic companies, seeking to bring a generic version of raloxifene to market prior to patent expiration, challenged the validity of the new medical use patent, arguing it would have been obvious to use raloxifene to treat bone loss. ${ }^{42}$ However, the district court concluded otherwise, and found that, particularly given the low bioavailability of the compound, it was not obvious for Lilly

433. Id. at 1332 .

434. Id.

435. Id.

436. Id. at 1338 .

437. 1999 FDA Approved Drugs, CENTERWATCH, https://www.centerwatch.com/druginformation/fda-approved-drugs/year/1999 [https://perma.cc/MNS8-ECTH] (last visited Mar. 21, 2017).

438. Id.

439. FDA Approves New Uses for Evista, HighBeAm Res. (Oct. 1, 2007), https://www.highbeam.com/doc/1G1-171018538.html [https://perma.cc/8CUT-AEV4].

440. Id.

441. "Claim 1 of the ' 086 patent is representative and provides: 'A method of inhibiting postmenopausal bone loss in a post-menopausal woman in need of treatment to prevent or treat postmenopausal osteoporosis comprising administering a single daily oral dose to said woman of an effective amount of [raloxifene] hydrochloride.'” Eli Lilly \& Co. v. Teva Pharm. USA, Inc., 619 F.3d 1329, 1335 (Fed. Cir. 2010) (quoting U.S. Patent No. 6,906,086 (filed May 27, 2003)).

442. Id. at 1336 . 
scientist to pursue and ultimately achieve success in use of the compound to treat bone loss. ${ }^{443}$ On appeal, a unanimous panel of the Federal Circuit agreed in Eli Lilly \& Co. v. Teva Pharmaceuticals USA. ${ }^{444}$

The Guidelines assert that patents on new medical uses amount to nothing more than an attempt by pharmaceutical companies to extend their monopoly on a product whose patent is about to expire. ${ }^{445}$ However, this objection fails to recognize that a tremendous amount of work and research is necessary to identify, characterize, and validate new uses of existing drugs to treat additional indications. In fact, there are great advantages to using the same product to treat multiple indications as opposed to using different drugs for each indication. By using a drug that has a track record in treatment of the first indication, it is possible to have a much greater knowledge of the characteristics of the drug, its safety profile, any potential problems that might be caused by drug interactions, etc. It makes no sense to denigrate the contribution to health care made by the development of second indications of a useful drug, and to characterize it as somehow unworthy of patent protection simply because it does not involve the use of an entirely novel pharmaceutical. Significantly, the scope of the patent on use of a known drug to treat a second indication is limited to that second indication, and as discussed above leaves open to the public use of the drug for the first indication as well as other indications.

To the extent the Guidelines suggest that development of a new use for a second indication is a lesser contribution to medicine than the development of an entirely novel product, ${ }^{446}$ it bears noting that the patent claims to a second indication are much narrower than a claim directed toward a new product. The scope of the second indication claim is in fact commensurate with the scope of the contribution, and should not raise public policy objections as suggested by the Guidelines.

The Guidelines argue that patentability of a use claim can be denied on the grounds it is a discovery, rather than an invention, because "the pharmacological effect is intrinsic to the compound." ${ }^{447}$ But any pharmacological invention can be characterized as a "discovery." As a general matter, any patent on a drug is premised on its pharmacological effect, which can be characterized as "intrinsic to the compound." But this should not implicate the patent eligibility of a new medical use, any more than it should implicate the patent eligibility of a product claim directed toward a newly discovered active ingredient.

The assertions that new medical uses lack technical character or industrial applicability simply because the effect takes place in the body is likewise difficult to understand. After all, as a general matter drugs are not rendered unpatentable simply because the only known application is for treatment of the body, and the Guidelines provide no rationale for specifically targeting new medical use

\footnotetext{
443. Id. at 1338 .

444. Id. at 1341 .

445. Guidelines, supra note 1 , at 42.

446. Id. at 44 .

447. $I d$.
} 
inventions in this regard. Furthermore, a claim directed toward a new medical use can be novel, so long as the claim is of an appropriate scope that encompasses neither the compound per se nor previously known medical uses.

\section{Analogy Processes and Methods of Treatment}

The Working Paper included sections targeting analogy processes and method of treatment claims, but these sections do not appear in the Guidelines, and for that reason these categories of invention will not be specifically addressed in this present Article. ${ }^{448}$

\section{CONCLUSION}

Given the important role pharmaceuticals play in improving the human condition, and the extreme cost and risk associated with developing new and improved pharmaceuticals, it is critically important that the law not impose overly strict requirements of patentability. To do so risks reducing the incentive for future innovation, and ultimately impoverishing the pipeline for the next generation of drugs. A U.K. court captured the concern nicely in its recent opinion in MedImmune v. Novartis when it stated:

One of the matters which it may be appropriate to take into account is whether it was obvious to try a particular route to an improved product or process. There may be no certainty of success but the skilled person might nevertheless assess the prospects of success as being sufficient to warrant a trial. In some circumstances this may be sufficient to render an invention obvious. On the other hand, there are areas of technology such as pharmaceuticals and biotechnology which are heavily dependent on research, and where workers are faced with many possible avenues to explore but have little idea if any one of them will prove fruitful. Nevertheless they do pursue them in the hope that they will find new and useful products. They plainly would not carry out this work if the prospects of success were so low as not to make them worthwhile. But denial of patent protection in all such cases would act as a significant deterrent to research. ${ }^{449}$

When considered in the abstract, it is easy to devalue the inventiveness of the categories of pharmaceutical innovation targeted by the Guidelines. However, as illustrated by the decisions surveyed in this Article, when courts delve deeply into the substance of these inventions they are often struck by the unpredictability and difficulty inherent in pharmaceutical innovation. I hope that this Article will provide some counterweight to balance the more radical, and in my view unwarranted, recommendations set forth in the Guidelines.

448. See Working Paper, supra note 2, at 16, 19.

449. [2012] EWCA (Civ) 1234 [90]. 